\title{
Controlled Synthesis of Well-Defined Polyaminoboranes on Scale Using a Robust and Efficient Catalyst
}

Claire N. Brodie, ${ }^{\text {If }}$ Timothy M. Boyd, ${ }^{\text {II }}$ Lia Sotorríos, David E. Ryan, Eimear Magee, Steven Huband, James S. Town, Guy C. Lloyd-Jones, David M. Haddleton,* Stuart A. Macgregor,* and Andrew S. Weller*

Cite This: J. Am. Chem. Soc. 2021, 143, 21010-21023

Read Online

ACCESS | Lill Metrics \& More | 回 Article Recommendations ｜（s Supporting Information

ABSTRACT: The air tolerant precatalyst, $[\mathrm{Rh}(\mathrm{L})(\mathrm{NBD})] \mathrm{Cl}([\mathbf{1}] \mathrm{Cl})\left[\mathrm{L}=\kappa^{3}-\right.$ $\left({ }^{i} \mathrm{Pr}_{2} \mathrm{PCH}_{2} \mathrm{CH}_{2}\right)_{2} \mathrm{NH}, \mathrm{NBD}=$ norbornadiene $]$, mediates the selective synthesis of $\mathrm{N}$-methylpolyaminoborane, $\left(\mathrm{H}_{2} \mathrm{BNMeH}\right)_{n}$, by dehydropolymerization of $\mathrm{H}_{3} \mathrm{~B} \cdot \mathrm{NMeH}_{2}$. Kinetic, speciation, and DFT studies show an induction period in which the active catalyst, $\mathrm{Rh}(\mathrm{L}) \mathrm{H}_{3}$ (3), forms, which sits as an outer-sphere adduct $\mathbf{3} \cdot \mathrm{H}_{3} \mathbf{B N M e H}_{2}$ as the resting state. At the end of catalysis, dormant $\mathrm{Rh}(\mathrm{L}) \mathrm{H}_{2} \mathrm{Cl}$ (2) is formed. Reaction of 2 with $\mathrm{H}_{3} \mathrm{~B} \cdot \mathrm{NMeH}_{2}$ returns 3, alongside the proposed formation of boronium $\left[\mathrm{H}_{2} \mathrm{~B}\left(\mathrm{NMeH}_{2}\right)_{2}\right] \mathrm{Cl}$. Aided by isotopic labeling, Eyring analysis, and DFT calculations, a mechanism is proposed in which the cooperative "PNHP" ligand templates dehydrogen-

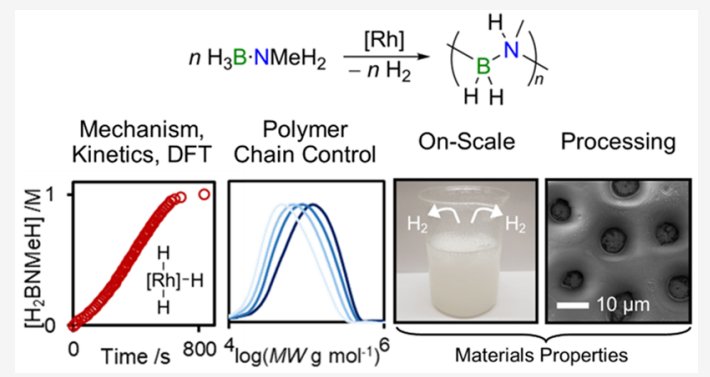
ation, releasing $\mathrm{H}_{2} \mathrm{~B}=\mathrm{NMeH}\left(\Delta G^{\ddagger}\right.$ calc $\left.=19.6 \mathrm{kcal} \mathrm{mol}^{-1}\right) . \mathrm{H}_{2} \mathrm{~B}=\mathrm{NMeH}$ is proposed to undergo rapid, low barrier, head-to-tail chain propagation for which 3 is the catalyst/initiator. A high molecular weight polymer is formed that is relatively insensitive to catalyst loading $\left(M_{\mathrm{n}} \sim 71000 \mathrm{~g} \mathrm{~mol}^{-1} ; \boxplus\right.$, of $\left.\sim 1.6\right)$. The molecular weight can be controlled using $\left[\mathrm{H}_{2} \mathrm{~B}\left(\mathrm{NMe}_{2} \mathrm{H}\right)_{2}\right] \mathrm{Cl}$ as a chain transfer agent, $M_{\mathrm{n}}=37900-78100 \mathrm{~g} \mathrm{~mol}^{-1}$. This polymerization is suggested to arise from an ensemble of processes (catalyst speciation, dehydrogenation, propagation, chain transfer) that are geared around the concentration of $\mathrm{H}_{3} \mathrm{~B} \cdot \mathrm{NMeH}_{2}$. TGA and DSC thermal analysis of polymer produced on scale $(10 \mathrm{~g}, 0.01 \mathrm{~mol} \%$ [1] Cl) show a processing window that allows for melt extrusion of polyaminoborane strands, as well as hot pressing, drop casting, and electrospray deposition. By variation of conditions in the latter, smooth or porous microstructured films or spherical polyaminoboranes beads $(\sim 100 \mathrm{~nm})$ result.

\section{INTRODUCTION}

Polymers with alternating $\mathrm{B}-\mathrm{N}$ main-chain backbones, the polyaminoboranes $\left(\mathrm{H}_{2} \mathrm{BNRH}\right)_{n}$, are inorganic analogues of polyolefins $\left(\mathrm{H}_{2} \mathrm{CCHR}\right)_{n}$, through the simple isosteric relationship between $\mathrm{BN}$ and $\mathrm{CC}$ (Scheme 1A). ${ }^{1-4}$ Polyolefins are technologically and societally ubiquitous, and their catalytic

Scheme 1. (A) Polyolefins versus Polyaminoboranes; (B) Synthesis of $\left(\mathrm{H}_{2} \mathrm{BNMeH}\right)_{n}$ Using $\operatorname{Ir}(\mathrm{POCOP}) \mathrm{H}_{2}$

(A)

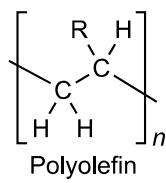

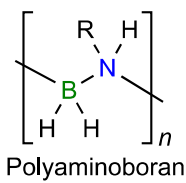

(B)

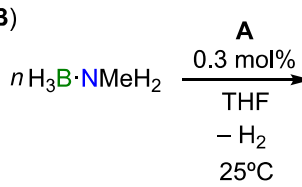

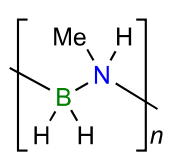
$M_{\mathrm{n}}$ up to $190,000 \mathrm{~g} / \mathrm{mol}$
$\theta=1.2$ to 2.9

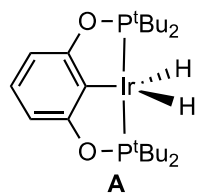

A synthesis from alkene monomers, and the resulting macromolecular structures, can be controlled using mechanism-led catalyst design. $^{5-9}$ Despite ill-defined $\left(\mathrm{H}_{2} \mathrm{BNH}_{2}\right)_{n}$ being known for decades from thermolysis of $\mathrm{H}_{3} \mathrm{~B} \cdot \mathrm{NH}_{3}$, ${ }^{10}$ polyaminoboranes are significantly less well-developed. In addition to the fundamental interest as new inorganic main chain polymeric materials, ${ }^{3,11}$ potential applications of polyaminoboranes are as piezoelectric materials, ${ }^{12,13}$ and processable polymeric precursors for boron-based preceramics ${ }^{14,15}$ and few-layer $h$-BN. ${ }^{16}$

The breakthrough reports of the metal catalyzed dehydropolymerization of the primary $\mathrm{N}$-alkyl amine-borane $\mathrm{H}_{3} \mathrm{~B}$. $\mathrm{NMeH}_{2}$ to give soluble, ${ }^{17}$ high molecular weight, ${ }^{18-20}$ $\left(\mathrm{H}_{2} \mathrm{BNMeH}\right)_{n}$ came in 2008, using the $\mathrm{Ir}(\mathrm{POCOP}) \mathrm{H}_{2}$ catalyst $\left[\mathrm{POCOP}=\kappa^{3}-\left(\mathrm{OP}^{\mathrm{t}} \mathrm{Bu}_{2}\right)_{2} \mathrm{C}_{6} \mathrm{H}_{3}\right](\mathrm{A}$, Scheme $1 \mathrm{~B})$ with $\mathrm{H}_{2}$ as

Received: October 14, 2021

Published: November 30, 2021

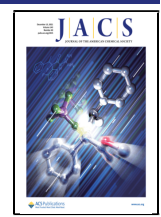


the only byproduct. Significant progress has been made since this report with regard to the range of transition metal precatalysts that promote dehydropolymerization, ${ }^{4,21-23}$ the scope of amine borane substrates, ${ }^{24-29}$ and the development of noncatalytic routes. ${ }^{30-32}$ In addition to A, notable catalysts for the dehydropolymerization of $\mathrm{H}_{3} \mathrm{~B} \cdot \mathrm{NRH}_{2}$ include those based upon $(\mathrm{CpZrCl})_{2}($ allenediyl $) ;{ }^{33} \mathrm{CoH}\left(\kappa^{4}-\mathrm{P}\left(\mathrm{CH}_{2} \mathrm{CH}_{2} \mathrm{PPh}_{2}\right)_{3}\right) ;{ }^{34}$ $\left({ }^{\mathrm{R}} \mathrm{PSCSP}^{\mathrm{R}}\right) \mathrm{Rh}(\mathrm{py})(\mathrm{H})(\mathrm{Cl})\left[{ }^{\mathrm{R}} \mathrm{PSCSP}^{\mathrm{R}}=\mathrm{C}_{6} \mathrm{H}_{4}-2,6-\left(\mathrm{SPR}_{2}\right)\right] ;{ }^{35}$ $\mathrm{Fe}\left(\mathrm{PhNCH}_{2} \mathrm{CH}_{2} \mathrm{NPh}\right)\left(\mathrm{Cy}_{2} \mathrm{PCH}_{2} \mathrm{CH}_{2} \mathrm{PCy}_{2}\right) ;{ }^{36} \mathrm{Cp}_{2}{ }_{2} \mathrm{TiCl}_{2}+2$ $\left.\times n-\mathrm{BuLi}^{28,37} \mathrm{ML}_{n}\left({ }^{i} \mathrm{Pr}_{2} \mathrm{PCH}_{2} \mathrm{CH}_{2}\right)_{2} \mathrm{NH}\right)\left(\mathrm{M}=\mathrm{Fe}{ }^{27,38,39}\right.$ $\left.\mathrm{Ru}^{40}{ }^{40} \mathrm{Co}^{41} \mathrm{~L}_{n}=\mathrm{PR}_{3} / \mathrm{CO} / \mathrm{H} / \mathrm{Cl}\right) ;$ and precatalysts based upon cationic $\left[\mathrm{Rh}\left(\mathrm{L}_{2}\right)\right]\left[\mathrm{BAr}_{4}{ }_{4}\right]\left[\mathrm{L}_{2}=\right.$ $\mathrm{Ph}_{2} \mathrm{PCH}_{2} \mathrm{CH}_{2} \mathrm{CH}_{2} \mathrm{PPh}_{2}{ }^{42}$ DPEphos, ${ }^{43,44}$ Xantphos-R ( $\mathrm{R}=$ $\left.\left.\mathrm{Ph},{ }^{i} \mathrm{Pr}\right) ;{ }^{45,46} \mathrm{Ar}^{\mathrm{F}}=3,5-\left(\mathrm{CF}_{3}\right)_{2} \mathrm{C}_{6} \mathrm{H}_{3}\right]$.

Despite this broad range of catalysts, the mechanism-led design of new systems for the dehydropolymerization of amine-boranes is challenging. It is difficult as any catalystsystem plays a dual role, ${ }^{18,40,47}$ holistically mediating two elementary processes of this cascade-like ${ }^{48}$ polymerization: the initial dehydrogenation of an amine-borane to form a transient and highly reactive aminoborane, i.e., $\mathrm{H}_{2} \mathrm{~B}=\mathrm{NRH},{ }^{32,49}$ and then chain initiation/propagation/termination likely operating by head-to-tail ${ }^{50} \mathrm{~B}-\mathrm{N}$ bond formation (Scheme 2). Computa-

Scheme 2. Generic Dehydropolymerization Process Using $\mathrm{H}_{3} \mathrm{~B} \cdot \mathrm{NMeH}_{2}{ }^{a}$

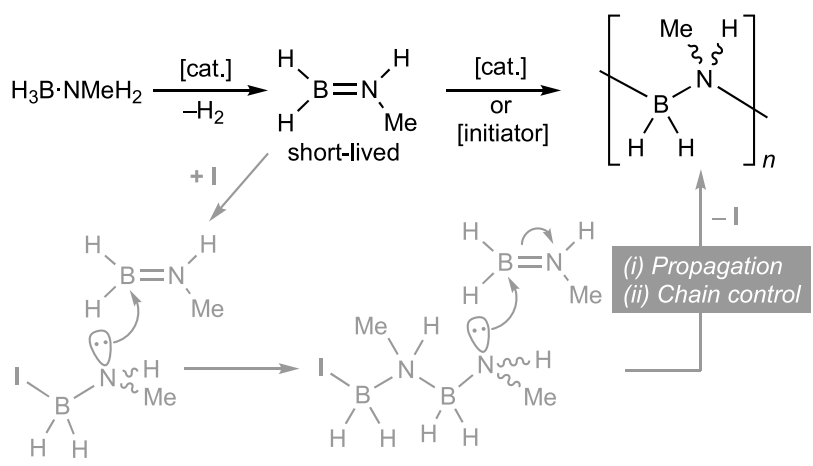

${ }^{a}$ Suggested head-to-tail propagation mechanism. I = catalyst initiator.

tional studies show such chain propagation to be an exergonic process with a very low barrier $(3-7 \mathrm{kcal} / \mathrm{mol})$ as initiated by a suitable nucleophile (e.g., A or amine) ${ }^{30,47}$ However, if these two processes are not geared well, an unselective dehydrocoupling produces borazines, $\mathrm{B}-\mathrm{N}$ cleavage products, or illdefined and insoluble polymer/material. ${ }^{4}$ A controlled $^{51}$ dehydropolymerization would ideally lead to the selective and high-yielding synthesis of well-defined, processable, polymeric products where the degree of polymerization, dispersity, and polymer macrostructure can all be systematically modified.

Kinetic and mechanistic studies of catalyzed dehydropolymerization invariably point to significant catalyst dependent complexity, including the possibility for either polymer chain $^{18,27,38,46}$ or step-growth ${ }^{28,29}$ processes. For example, recent work in our laboratories using the cationic [ $[\mathrm{Rh}$ (DPEphos) $\left.\left(\eta-\mathrm{H}_{2} \mathrm{BNMeCH}_{2} \mathrm{CH}_{2} t \mathrm{Bu}\right)\right]\left[\mathrm{BAr}^{\mathrm{F}}{ }_{4}\right]$ catalyst $^{43,44}$ has revealed an induction process, nonliving chain-growth propagation, partial order in catalyst, and an inverse relationship between catalyst loading and degree of polymerization, with $\mathrm{H}_{2}$ acting to control chain length. Detailed speciation and mechanistic studies resolve many of these complexities by revealing the true catalyst resting state as a dimeric, neutral, hydride $\left[\mathrm{Rh}(\mathrm{DPEphos}) \mathrm{H}_{2}\right]_{2}$ arising from amine-promoted hydride transfer, ${ }^{35,52,53}$ that arises from $\mathrm{B}-\mathrm{N}$ bond cleavage of $\mathrm{H}_{3} \mathrm{~B} \cdot \mathrm{NMeH}_{2}$. Moreover, a likely coproduct of this hydride transfer, boronium $\left[\mathrm{H}_{2} \mathrm{~B}\left(\mathrm{NMeH}_{2}\right)_{2}\right]\left[\mathrm{BAr}_{4}^{\mathrm{F}}\right]$, was shown to act as a chain-length control agent, being proposed to protonate the amine-terminus of a growing polymer chain that arises from the low barrier head-to-tail $\mathrm{B}-\mathrm{N}$ chain-forming events (e.g., Scheme 2). Despite these detailed insights, the synthetically accessible precursor to $\left[\mathrm{Rh}(\mathrm{DPEphos}) \mathrm{H}_{2}\right]_{2}$, $\mathrm{Rh}(\mathrm{DPEphos})\left(\eta^{3}-\mathrm{H}_{2} \mathrm{CPh}\right),{ }^{44}$ is not straightforward to prepare as it is air and thermally sensitive, while the precise mechanism of amine-borane dehydrogenation remains unresolved.

We were interested to explore whether chain-length control could be extended to potentially more robust $\left.\mathrm{ML}_{n}\left({ }^{i} \mathrm{Pr}_{2} \mathrm{PCH}_{2} \mathrm{CH}_{2}\right)_{2} \mathrm{NH}\right)$-type systems, that have been shown to operate via ligand cooperative ${ }^{23,54}$ amine-borane dehydrogenation mechanisms. Inspired by the work of Schneider and Beweries on such group 8 catalyst systems, ${ }^{27,38-40}$ and our own recent report using $\mathrm{Co}$ (II) precatalysts, ${ }^{41}$ we now report the simple, easy to assemble, tolerant-to-air, precatalyst $\left[\mathrm{Rh}\left\{\left({ }^{i} \mathrm{Pr}_{2} \mathrm{PCH}_{2} \mathrm{CH}_{2}\right){ }_{2} \mathrm{NH}\right\}(\mathrm{NBD})\right]$ $\mathrm{Cl},[\mathbf{1}] \mathrm{Cl}$, for the dehydropolymerization of commercial, as supplied, $\mathrm{H}_{3} \mathrm{~B} \cdot \mathrm{NMeH}_{2}$ in THF solvent, Chart $1 .[\mathbf{1}] \mathrm{Cl}$

\section{Chart 1. This Work}

Air tolerant catalysis at low loadings $(<0.5 \mathrm{~mol} \%)$
Easy to assemble using commerical starting materials
Selective for $\left[\mathrm{H}_{2} \mathrm{BNMeH}\right]_{\mathrm{n}}\left(\mathrm{M}_{\mathrm{n}} \sim 70,000 \mathrm{~g} / \mathrm{mol} ; \oplus \sim 1.6\right)$
Speciation and detailed mechansim
Chain control using $\left[\mathrm{H}_{2} \mathrm{~B}\left(\mathrm{NMe}_{2} \mathrm{H}\right)_{2}\right] \mathrm{Cl}$

promotes the fast (minutes, $298 \mathrm{~K}$ ), efficient $(1-0.01 \mathrm{~mol}$ $\%)$, and selective production of well-defined $\left(\mathrm{H}_{2} \mathrm{BNMeH}\right)_{n}$ in high yield. Combined kinetic, isotopic replacement, DFT, and speciation studies reveal both on- and off-cycle species, and thus the mechanism of dehydrogenation. Using the boronium salt $\left[\mathrm{H}_{2} \mathrm{~B}\left(\mathrm{NMe}_{2} \mathrm{H}\right)_{2}\right] \mathrm{Cl}$ as a convenient chain control agent allows for control of the degree of polymerization, and thus exploration of the polymer physical properties (TGA and DSC) versus $M_{n} / \oplus$. We also demonstrate the straightforward synthesis on $10 \mathrm{~g}$ scale of $\left(\mathrm{H}_{2} \mathrm{BNMeH}\right)_{n}$ at low catalyst loadings $(0.01 \mathrm{~mol} \%)$ and the exploration of a variety of materials processing methods for the resulting $\left(\mathrm{H}_{2} \mathrm{BNMeH}\right)_{n}$, such as melt extrusion and thin-film deposition.

\section{RESULTS AND DISCUSSION}

2.1. Precatalyst Synthesis and Reactivity with $\mathrm{H}_{2}$. The orange precatalyst $\left[\mathrm{Rh}\left\{\kappa^{3}-\left({ }^{i} \mathrm{Pr}_{2} \mathrm{PCH}_{2} \mathrm{CH}_{2}\right)_{2} \mathrm{NH}\right\}\left(\eta^{2} \eta^{2}-\mathrm{NBD}\right)\right]$ $\mathrm{Cl},[1] \mathrm{Cl}$, was prepared by reaction of $[\mathrm{Rh}(\mathrm{NBD}) \mathrm{Cl}]_{2}$ with $\left({ }^{i} \mathrm{Pr}_{2} \mathrm{PCH}_{2} \mathrm{CH}_{2}\right)_{2} \mathrm{NH}$ in concentrated THF solution overnight at $298 \mathrm{~K}$, a solvent from which it precipitates as an analytically pure powder in $90 \%$ yield on $0.5 \mathrm{~g}$ scale (Figure 1). A singlecrystal X-ray diffraction study reveals a cationic 18-electron pseudo-trigonal bipyramidal $\mathrm{Rh}(\mathrm{I})$ center, a facially coordinated $\kappa^{3}$-PNHP ligand, and the chloride counterion hydrogen bonded $^{55}$ to the $\mathrm{N}-\mathrm{H}$ proton $(\mathrm{H} \cdots \mathrm{Cl}, 2.32(2) \AA$, sum van der Waals radii $\left.=3.02 \AA^{56}\right)$. Solution NMR data $\left(\mathrm{CD}_{2} \mathrm{Cl}_{2}\right)$ show a single ${ }^{31} \mathrm{P}$ environment in the ${ }^{31} \mathrm{P}\left\{{ }^{1} \mathrm{H}\right\}$ NMR spectrum $[\delta$ 48.0, $J(\mathrm{RhP})=124 \mathrm{~Hz}]$. In the ${ }^{1} \mathrm{H}$ NMR spectrum a single broad 


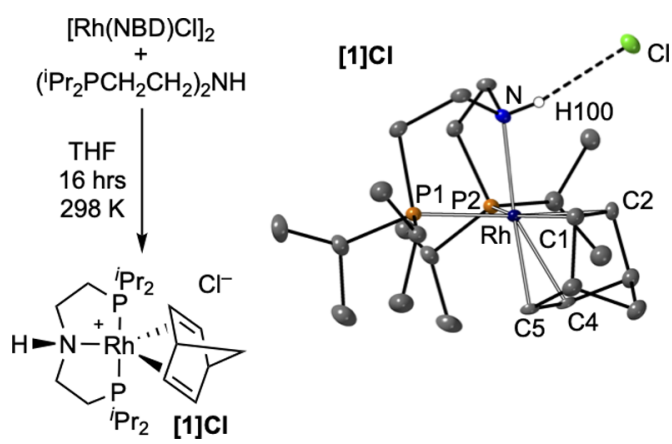

Figure 1. Synthesis of $[\mathbf{1}] \mathbf{C l}$. Molecular structure of $[\mathbf{1}] \mathbf{C l}$; displacement ellipsoids shown at $50 \%$, only $\mathrm{N}-\mathrm{H}$ hydrogen atoms shown. See the Supporting Information.

alkene $\mathrm{CH}$ resonance, and a single bridging methylene $(\delta 3.66$, $4 \mathrm{H} ; 1.12,2 \mathrm{H}$ respectively) and four different ${ }^{i} \mathrm{Pr}$ methyl environments are observed, suggesting rapid rotation of the NBD ligand at $298 \mathrm{~K}$. The $\mathrm{N}-\mathrm{H}$ group is observed at $\delta 6.99$, showing the $\mathrm{N}-\mathrm{H} \cdots \mathrm{Cl}$ hydrogen bond is retained in $\mathrm{CD}_{2} \mathrm{Cl}_{2}$ solution.

A common method for activating " $\mathrm{Rh}(\mathrm{NBD})$ "-type precatalysts is hydrogenation to form the catalyst in situ. 6 18-electron [1] Cl reacts slowly with $\mathrm{H}_{2}$ (7 days, 4 bar $\mathrm{H}_{2}, 70$ $\left.{ }^{\circ} \mathrm{C}, 1,2-\mathrm{F}_{2} \mathrm{C}_{6} \mathrm{H}_{4}\right)$ to give the $\mathrm{Rh}(\mathrm{III})$ complex $\mathrm{Rh}\left\{\kappa^{3}-\right.$ $\left.\left({ }^{i} \mathrm{Pr}_{2} \mathrm{PCH}_{2} \mathrm{CH}_{2}\right)_{2} \mathrm{NH}\right\} \mathrm{H}_{2} \mathrm{Cl}$, 2, in moderate yield (42\%) as a white powder after workup, Figure 2. A more convenient route

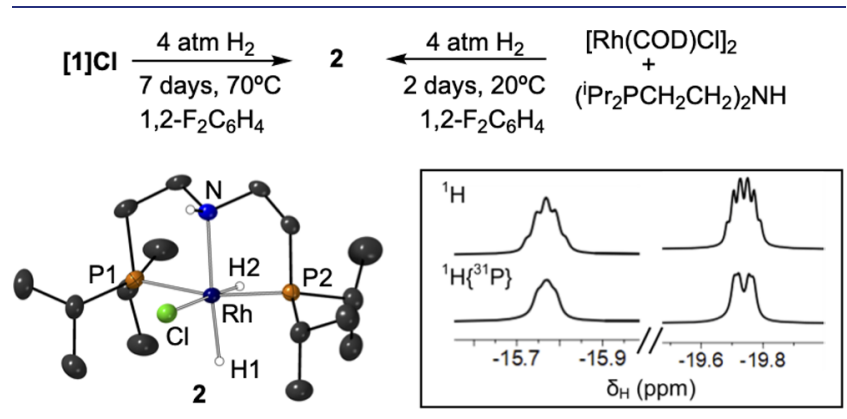

Figure 2. Synthesis of $\mathbf{2}$ and its molecular structure (displacement ellipsoids shown at $50 \%$, selected $\mathrm{H}$ shown). See the Supporting Information for selected metrical data. Inset shows the hydride signals in the ${ }^{1} \mathrm{H} /{ }^{1} \mathrm{H}\left\{{ }^{31} \mathrm{P}\right\}$ NMR spectra $\left(\mathrm{C}_{6} \mathrm{D}_{6}\right)$.

to 2 involves direct combination of $[\mathrm{Rh}(\mathrm{COD}) \mathrm{Cl}]_{2}$, the PNHP ligand, and $\mathrm{H}_{2}$ (2 days at $298 \mathrm{~K}, 1,2-\mathrm{F}_{2} \mathrm{C}_{6} \mathrm{H}_{4}$ ) to give 2 in $85 \%$ isolated yield as an analytically pure microcrystalline solid. Complex 2 was characterized by single-crystal X-ray diffraction that shows a meridional $\kappa^{3}$-PNHP ligand, with the now coordinated chloride ligand syn to the $\mathrm{N}-\mathrm{H}$ group and two hydride ligands (located, $R(2 \sigma)=3.2 \%$ ). NMR data (THF- $d_{8}$ ) are in full agreement with this structure: a single environment is observed in the ${ }^{31} \mathrm{P}\left\{{ }^{1} \mathrm{H}\right\}$ NMR spectrum $[\delta 75.7, J(\mathrm{RhP})=$ $115 \mathrm{~Hz}]$, in the ${ }^{1} \mathrm{H}$ NMR spectrum the $\mathrm{NH}$ group is observed at $\delta 3.69$, and two chemically inequivalent hydrides, $\delta-16.32$ (H1) and $\delta-19.84(\mathrm{H} 2)$, show coupling to each other, ${ }^{31} \mathrm{P}$, and ${ }^{103} \mathrm{Rh}$, Figure 2. A ${ }^{1} \mathrm{H}$ NOESY experiment shows no correlation between $\mathrm{NH}$ and hydride signals. As we show such correlations are operative when a hydride ligand is syn to the $\mathrm{NH}$ (vide infra, complex 3 ), we use their absence in 2 as confirmation that the structure observed in the solid-state is retained in solution. Surprisingly $\mathbf{2}$ is a rare example of a crystallographically characterized $\mathrm{Rh}(\mathrm{PNHP})$ complex. $^{57 \mathrm{a}} \mathrm{Co}$ and Ir analogues of $\mathbf{2}$ are known. ${ }^{57 \mathrm{~b}, \mathrm{c}}$

As will be discussed in Section 2.3, complex 2 is a key species observed in the catalytic manifold of $\mathrm{H}_{3} \mathrm{~B} \cdot \mathrm{NMeH}_{2}$ dehydropolymerization using $[\mathbf{1}] \mathbf{C l}$ as a precatalyst. Complex [1] Cl reacts with $\mathrm{H}_{3} \mathrm{~B} \cdot \mathrm{NMeH}_{2}$ relatively quickly under such conditions, so that complete consumption occurs after only $300 \mathrm{~s}$ to ultimately afford $\mathbf{2}$ and polyaminoboranes, reflected in the short induction periods observed in catalysis (Section 2.2) starting from $[\mathbf{1}] \mathbf{C l}$. This is in contrast to the very slow reaction with $\mathrm{H}_{2}$, this being similar to that reported for related 5 coordinate, 18-electron, $\mathrm{Rh}(\mathrm{I})$ diene complexes. ${ }^{57,58}$ Attempts to make complexes analogous to $[\mathbf{1}] \mathbf{C l}$ or $\mathbf{2}$ with the $\mathrm{PNMeP}{ }^{40}$ ligand were unsuccessful-leading to intractable mixtures of products.

2.2. Baselining the Dehydropolymerization of $\mathrm{H}_{3} \mathrm{~B}$ $\mathrm{NMeH}_{2}$ : Conversion, Selectivity, Reaction Conditions. With precatalyst $[\mathbf{1}] \mathbf{C l}$ in hand, we tested its efficacy for dehydropolymerization using commercially sourced, as supplied, $\mathrm{H}_{3} \mathrm{~B} \cdot \mathrm{NMeH}_{2}$ in THF solvent (from a drying column). The use of THF is advantageous compared with commonly used $1,2-\mathrm{F}_{2} \mathrm{C}_{6} \mathrm{H}_{4}$, as $\mathrm{H}_{3} \mathrm{~B} \cdot \mathrm{NMeH}_{2}$ is much more soluble in THF $\left(\sim 0.22^{46}\right.$ and $\sim 16 \mathrm{M},{ }^{59}$ respectively $)$. The catalyst was trialed under conditions of $\mathrm{H}_{2}$ evolution measurement (eudiometer, jacketed Schlenk at $293 \mathrm{~K}$ ) to establish reaction progress. This was done both with and without special precautions for ingress of air, and also in a vial open to the air (Table 1). Under all conditions, using $0.5 \mathrm{~mol} \%[\mathbf{1}] \mathbf{C l}$ (1 M

Table 1. GPC Characterization Data for Different Conditions Using Precatalyst $[1] \mathrm{Cl}^{a}$

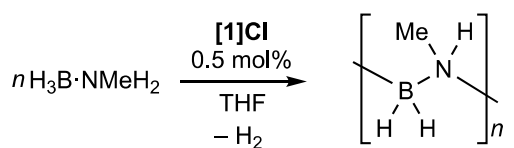

$\begin{array}{ccccc}\text { conditions } & \begin{array}{c}\text { conversion } \\ (\text { selectivity })^{b}\end{array} & \begin{array}{c}M_{\mathrm{n}}{ }^{c} \\ \left(\mathrm{~g} \mathrm{~mol}^{-1}\right)\end{array} & Ð & \begin{array}{c}\text { yield (\%) } \\ (\mathrm{mg})^{d}\end{array} \\ \text { eudiometer }^{e} & 99(98) & 73200 & 1.8 & 79(85) \\ \text { eudiometer }^{f} & 98(99) & 70800 & 1.6 & 96(103) \\ \text { open vial }^{f, g} & 100(99) & 68500 & 1.7 & 89(205)\end{array}$

${ }^{a} 1 \mathrm{M} \mathrm{H}_{3} \mathrm{~B} \cdot \mathrm{NMeH}_{2}(112 \mathrm{mg}), 0.5 \mathrm{~mol} \%[1] \mathrm{Cl}, 293 \mathrm{~K}$, THF $(2.5$ $\mathrm{mL}) .{ }^{b}$ Measured using ${ }^{11} \mathrm{~B}$ NMR spectroscopy by sampling the reaction mixture, \%. ${ }^{c} \mathrm{GPC}$ relative to polystyrene standards. ${ }^{d}$ Isolated polymer. ${ }^{e}$ Set up under Ar initially. ${ }^{f}$ No special precautions taken for the ingress of air during set up. ${ }^{g} 224 \mathrm{mg}$ scale, $30 \mathrm{~min}$ (unoptimized).

$\left.\mathrm{H}_{3} \mathrm{~B} \cdot \mathrm{NMeH}_{2}\right)$, polyaminoborane $\left(\mathrm{H}_{2} \mathrm{BNMeH}\right)_{n}$ is selectively produced in high isolated yield, by precipitation from pentane, with a consistent degree of polymerization $\left(M_{\mathrm{n}} \sim 71000 \mathrm{~g}\right.$ $\left.\mathrm{mol}^{-1}\right)$ and dispersity $(Ð \sim 1.7)$. The reactions take $\sim 10 \mathrm{~min}$ and are accompanied by vigorous $\mathrm{H}_{2}$ evolution (Movie S1). Eudiometric measurement showed 1 equiv of $\mathrm{H}_{2}$ was released. Figure S1 shows overlaid GPC data of the isolated polymer. NMR spectra $\left(\mathrm{CDCl}_{3}\right.$, Figure $\left.\mathrm{S} 45-49\right)$ are very similar to those previously reported. ${ }^{18,38,46}$ For example a broad peak is observed in the ${ }^{11} \mathrm{~B}$ NMR spectrum $(\delta-6.7),\left\{\mathrm{H}_{2} \mathrm{BNMeH}\right\}$ signals in the ${ }^{1} \mathrm{H}$ NMR spectrum, ${ }^{60}$ and broad and sharper $\mathrm{NMe}$ signals in the ${ }^{13} \mathrm{C}\left\{{ }^{1} \mathrm{H}\right\} \mathrm{NMR}$ spectrum, that may relate to polymer tacticity. ${ }^{18}$ There was no evidence for in situ depolymerization $^{27,28}$ up to $2 \mathrm{~h}$ after $\mathrm{H}_{2}$ evolution had stopped. Isolated polymer is air-stable for 6 months $\left({ }^{11} \mathrm{~B}\right.$ NMR spectroscopy, GPC). [1] Cl thus presents a robust and reliable 
catalyst system. The degree of polymerization is unaffected by the $\mathrm{H}_{2}$ atmosphere that is quickly established under eudiometric conditions, unlike for some cationic $\mathrm{Rh}$-based precatalysts, where significantly smaller degrees of polymerization are noted. ${ }^{43-45}$

2.3. Kinetics of $\mathrm{H}_{2}$ Release, Variation in Catalyst Loading, and On-Cycle Speciation. With the efficacy of $[1] \mathrm{Cl}$ as a dehydropolymerization precatalyst established, the kinetics of $\mathrm{H}_{2}$ evolution were interrogated. This is a reasonable proxy for the dehydrogenation of $\mathrm{H}_{3} \mathrm{~B} \cdot \mathrm{NMeH}_{2}$ to form $\mathrm{H}_{2} \mathrm{~B}=$ $\mathrm{NMeH}$ given the high selectivity and conversions measured. Figure 3 shows kinetic plots using different precatalyst loadings

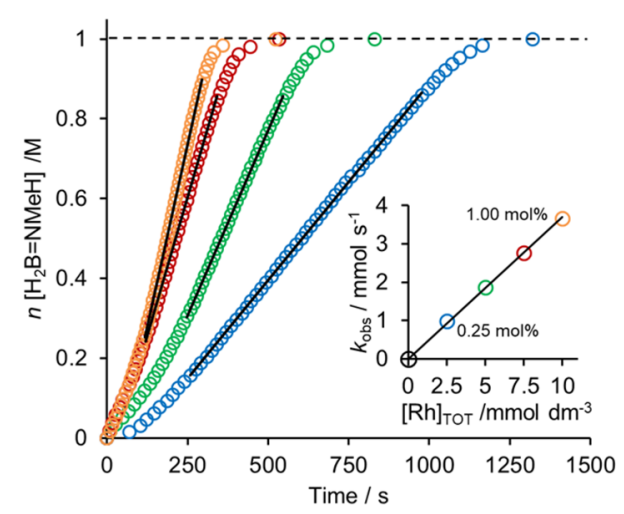

Figure 3. $\mathrm{H}_{2} \mathrm{~B}=\mathrm{NMeH}$ equivalents from $\mathrm{H}_{2}$ evolution (eudiometer) for the dehydropolymerization of $\mathrm{H}_{3} \mathrm{~B} \cdot \mathrm{NMeH}_{2}(1 \mathrm{M}$, THF, $293 \mathrm{~K}$ ) varying $[\mathrm{Rh}]_{\text {Tот }}$ using $[\mathbf{1}] \mathrm{Cl}$. Lines are of best fit in the pseudo-zeroorder region. Dotted line represents 1 equiv of $\mathrm{H}_{2}$. Inset shows $[\mathrm{Rh}]_{\text {total }}$ versus $k_{\text {obs }}$.

Table 2. Rate Constants for $\mathrm{H}_{2}$ Evolution, and Polymer Characterization, with Changing mol \% of $[1] \mathrm{Cl}^{a}$

$\begin{array}{ccccc}\begin{array}{c}{[\mathrm{Rh}]_{\text {total }}} \\ (\mathrm{mol} \mathrm{\% )}\end{array} & \begin{array}{c}k_{\text {obs }}\left(\mathrm{M} \mathrm{s}^{-1}\right) \\ \left(\times 10^{-3}\right)\end{array} & \begin{array}{c}M_{\mathrm{n}}{ }^{b} \\ \left(\mathrm{~g} \mathrm{~mol}^{-1}\right)\end{array} & Ð & \begin{array}{c}\text { selectivity } \\ (\% \text { yield })^{c}\end{array} \\ 0.25 & 0.99(1) & 74600 & 1.8 & 97(97) \\ 0.50 & 1.86(1) & 70800 & 1.6 & 99(89) \\ 0.75 & 2.77(1) & 70200 & 1.6 & 95(89) \\ 1.00 & 3.67(2) & 71200 & 1.6 & 95(93)\end{array}$

${ }^{a} 1 \mathrm{M} \mathrm{H}_{3} \mathrm{~B} \cdot \mathrm{NMeH}_{2}(110 \mathrm{mg})$, jacketed Schlenk at $293 \mathrm{~K}$, THF $(2.5$ $\mathrm{mL}$ ). No special precautions taken for the ingress of air during set up. ${ }^{b} \mathrm{GPC}$ relative to polystyrene standards. ${ }^{c}$ Measured using ${ }^{11} \mathrm{~B}$ NMR spectroscopy by sampling the reaction mixture, $\%$ yield of isolated polymer.

( 0.25 to $1 \mathrm{~mol} \%, 1 \mathrm{M} \mathrm{H} \mathrm{H}_{3} \mathrm{~B} \cdot \mathrm{NMeH}_{2}$ ), and Table 2 gives calculated $k_{\mathrm{obs}}$ and polymer characterization data. Figure S4 presents overlaid GPC data for isolated polymer. There is no evidence for the formation of $\mathrm{Rh}_{(s)}$, while a $\mathrm{Hg}$ drop test and substoichiometric $\mathrm{PMe}_{3}$ experiments are consistent with a homogeneous catalyst system operating (Figure S3). ${ }^{61}$ Recharging (100 equiv) resulted in immediate, fast catalysis with no induction period, while changing $\left[\mathrm{H}_{3} \mathrm{~B} \cdot \mathrm{NMeH}_{2}\right]$ to 1.5 $\mathrm{M}(0.5 \mathrm{~mol} \%[\mathbf{1}] \mathrm{Cl})$ resulted in no change in $k_{\mathrm{obs}}$ but a shorter induction period (Figure S5).

These data are notable in five ways: (i) there is an induction period that gets longer with lower catalyst loadings; ${ }^{62}$ (ii) postinduction there is a significant pseudo-zero-order regime that decelerates at high conversions; (iii) there is a first order relationship of $k_{\mathrm{obs}}$ with $[\mathrm{Rh}]_{\text {total }}$ (inset) indicative of no significant nuclearity equilibria; ${ }^{43,44,63}$ (iv) the degree of polymerization and dispersity is insensitive to catalyst loading $\left(M_{\mathrm{n}} \sim 71000 \mathrm{~g} \mathrm{~mol}^{-1}, Ð \sim 1.6\right)$; $(\mathrm{v})$ the reaction is relatively fast, so that even at $0.25 \mathrm{~mol} \%\left(1 \mathrm{M} \mathrm{H}_{3} \mathrm{~B} \cdot \mathrm{NMeH}_{2}\right)$ complete conversion is observed in $20 \mathrm{~min}$.

The catalyst system ( $1 \mathrm{~mol} \%,[1] \mathrm{Cl}$, THF- $\left.d_{8}\right)$ was interrogated by periodic sampling and analysis by ${ }^{31} \mathrm{P}\left\{{ }^{1} \mathrm{H}\right\}$ and ${ }^{1} \mathrm{H}$ NMR spectroscopy on cooling the sample to $185 \mathrm{~K}$ to effectively halt turnover and mitigate against $\mathrm{H}_{2}$ pressure buildup in a closed system. Carefully controlled rapid warming to $293 \mathrm{~K}$ restarted catalysis. Figure 4 shows how the speciation

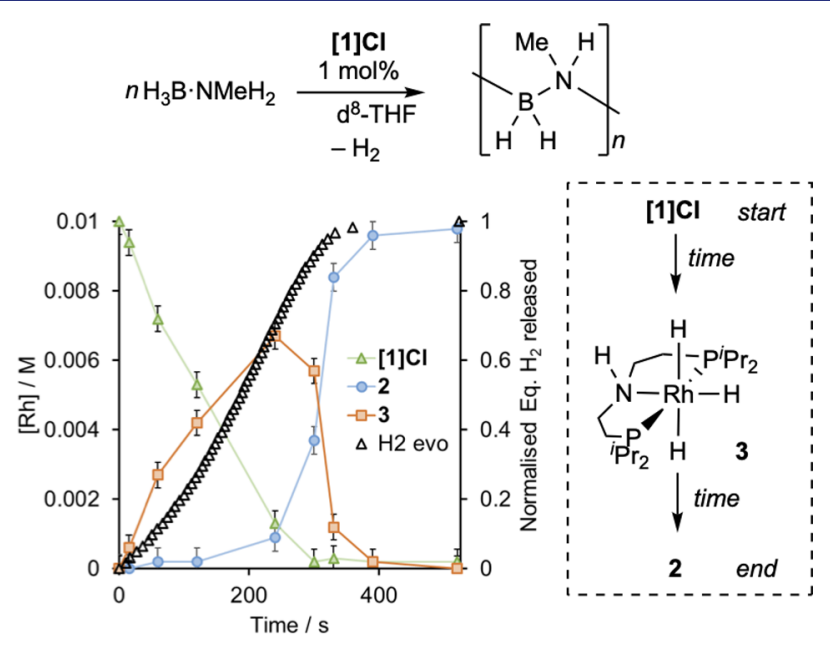

Figure 4. Temporal plot of speciation during catalysis as measured using ${ }^{1} \mathrm{H},{ }^{31} \mathrm{P}\left\{{ }^{1} \mathrm{H}\right\}$ NMR spectroscopy at $185 \mathrm{~K}\left(1 \mathrm{~mol} \%\right.$, THF- $\left.d_{8}\right)$ and $\mathrm{H}_{2}$ evolution for catalyst $[\mathbf{1}] \mathbf{C l}$.

of this system evolves with time, overlaid with separate $\mathrm{H}_{2}$ evolution measurements to chart progress. This shows the steady consumption of $[\mathbf{1}] \mathbf{C l}$ to form a new dominant complex, 3. At the late stages of catalysis, where there is a rate deceleration, the concentration of 3 drops rapidly to be replaced by 2 -which becomes the only organometallic species observed at the end of catalysis. The sigmoidal evolution of the overall kinetics thus reflects catalyst speciation, and suggests that complex 3 represents the catalyst resting state. Figures S29 and $\mathrm{S} 30$ show the salient ${ }^{1} \mathrm{H}$ and ${ }^{31} \mathrm{P}\left\{{ }^{1} \mathrm{H}\right\}$ NMR spectra. Notably, complex $\mathbf{2}$ is present in low concentrations from early in catalysis, while $\mathbf{3}$ is never the sole organometallic component, reaching a maximum of $\sim 70 \%$ of $[\mathrm{Rh}]_{\text {total }}$ after 240 s, with the mass balance shared equally between precatalyst $[\mathbf{1}] \mathbf{C l}$ and eventual final product 2 .

The new species, 3 , was initially identified in situ by three, equal integral, hydride signals being observed at $\delta-8.42$, -9.52, and -18.39 in the ${ }^{1} \mathrm{H}$ NMR spectrum, even at very early stages of catalysis (e.g., $15 \mathrm{~s}$ ), the intensities of which track with a new signal in the ${ }^{31} \mathrm{P}\left\{{ }^{1} \mathrm{H}\right\} \mathrm{NMR}$ spectrum at $\delta$ $88.6[J(\mathrm{RhP})=112 \mathrm{~Hz}]$. These data identify 3 as $\left.\mathrm{Rh}\left\{\kappa^{3}{ }^{i} \mathrm{Pr}_{2} \mathrm{PCH}_{2} \mathrm{CH}_{2}\right)_{2} \mathrm{NH}\right\} \mathrm{H}_{3}$. As the reaction evolves the hydride signals subtly, but progressively, shift: so close to the end of catalysis at low $\left[\mathrm{H}_{3} \mathrm{~B} \cdot \mathrm{NMeH}_{2}\right](300 \mathrm{~s})$, they are observed at $\delta-8.52,-8.93$, and -18.27 . These data are very similar to independently in situ synthesized, pale yellow 3 (eq $1)$ measured at $185 \mathrm{~K}(\delta-8.53,-8.83$, and -18.24$)$, for which the hydride signals were individually assigned, Figure 5 , aided by NOESY experiments. ${ }^{64}$ Signals due to complexes $[\mathbf{1}] \mathbf{C l}$ or 2 
do not change significantly as catalysis proceeds. The Co and Ir analogues of 3 are known. ${ }^{57 \mathrm{~b}, \mathrm{c}}$
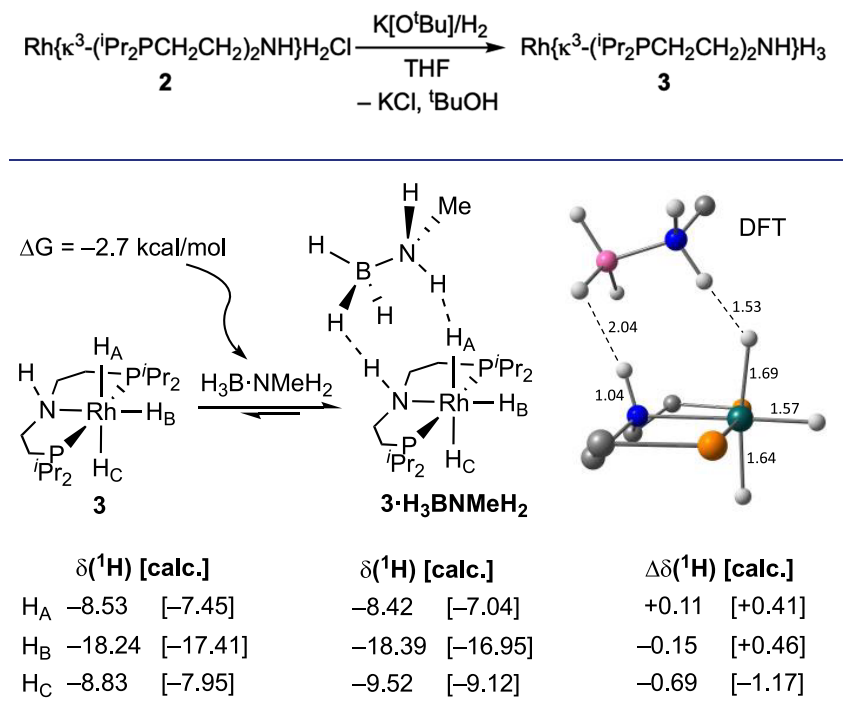

$$
\begin{array}{ll}
\delta\left({ }^{1} \mathbf{H}\right) \text { [calc. } \\
-8.42 & {[-7.04]} \\
-18.39 & {[-16.95]} \\
-9.52 & {[-9.12]}
\end{array}
$$

$$
\begin{array}{cc}
\Delta \delta\left({ }^{1} \mathbf{H}\right) & \text { [calc. }] \\
+0.11 & {[+0.41]} \\
-0.15 & {[+0.46]} \\
-0.69 & {[-1.17]}
\end{array}
$$

Figure 5. Proposed equilibrium between $\mathbf{3}$ and $\mathbf{3} \cdot \mathbf{H}_{3} \mathbf{B N M e H}$, DFT calculated structure of the adduct $\left({ }^{i} \mathrm{Pr}\right.$ groups and backbone $\mathrm{H}$ atoms omitted for clarity), and comparison of experimental and calculated chemical shifts (B3LYP/TZP/ZORA).

These data suggest $\mathrm{H}_{3} \mathrm{~B} \cdot \mathrm{NMeH}_{2}$ interacts with 3 via $\mathrm{H} \cdots \mathrm{H}$ dihydrogen bonds ${ }^{65}$ to form the outer-sphere adduct 3 . $\mathbf{H}_{3} \mathbf{B N M e H}_{2}$, the position of this rapid equilibrium being dependent on $\left[\mathrm{H}_{3} \mathrm{~B} \cdot \mathrm{NMeH}_{2}\right]$. DFT calculations (see Scheme 5 for method) confirm that such an adduct is thermodynamically favored ( $\Delta G=-2.7 \mathrm{kcal} / \mathrm{mol}$ ), and also show that the largest chemical shift change is associated with $\mathrm{H}_{C}$, as experimentally determined, Figure $5 .^{66}$ While such adducts have been proposed computationally as intermediates in amine borane dehydrogenation, ${ }^{27,39,40,67}$ they are rarely observed in solution. $^{88,69}$

Given that the chloride-containing complex $\mathbf{2}$ is observed to be formed during turnover conditions, and is the final organometallic complex at the end, its role as a precatalyst was investigated. Under the same conditions as for $[\mathbf{1}] \mathbf{C l}$, dehydropolymerization was followed by $\mathrm{H}_{2}$ evolution and catalyst speciation by NMR spectroscopy.

Figure 6 shows that there is no appreciable induction period for $\mathrm{H}_{2}$ evolution, zero-order kinetics are observed, and 1 equiv of hydrogen is released. Noticeable at $0.25 \mathrm{~mol} \%$ loading is an initial burst of faster turnover, followed by a slower zero order regime. Moreover, $k_{\mathrm{obs}}$ measured for $[\mathrm{Rh}]_{\mathrm{TOT}}$ at $1,0.5$, and $0.25 \mathrm{~mol} \%$ (zero order regime) do not scale in a simple first order relationship: $7.50(1) \times 10^{-3}, 2.76(1) \times 10^{-3}$, and $0.60(1) \times 10^{-3} \mathrm{M} \mathrm{s}^{-1}$, respectively. Polyaminoborane was formed in all cases, but selectivity (83-94\%), molecular weight $\left(M_{\mathrm{n}}=49000-71000 \mathrm{~g} \mathrm{~mol}^{-1}\right)$, and dispersity (1.6-1.9) were not as consistent as when using $[\mathbf{1}] \mathbf{C l}$ (Table S4) over different catalyst loadings.

These observations suggest the involvement of a trace reactant that disproportionately affects lower catalyst loadings of 2 but not $[\mathbf{1}] \mathbf{C l}$, the concentration of which can be estimated from a $k_{\text {obs }} /[\mathrm{Rh}]_{\text {TOT }}$ plot as $\sim 0.0019 \mathrm{M}$ (Figure S7). We suggest $\mathrm{H}_{2} \mathrm{O}$ as the source, from the column-dried THF: a concentration confirmed by Karl Fischer titration ( $30 \mathrm{ppm})$. Adjusting $[\mathrm{Rh}]_{\text {total }}$ for this leads to a first-order relationship with $k_{\text {obs }}$ that passes through the origin (Figure 6, inset A). We

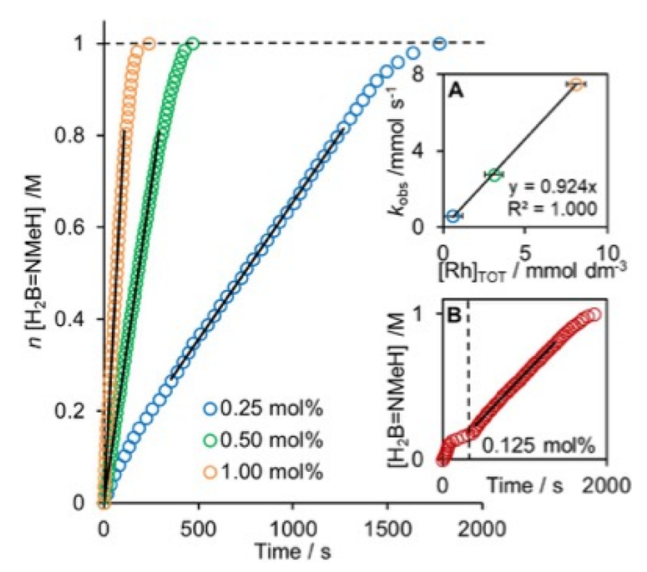

Figure 6. $\mathrm{H}_{2} \mathrm{~B}=\mathrm{NMeH}$ equivalents from $\mathrm{H}_{2}$ evolution (eudiometer) for the dehydropolymerization of $\mathrm{H}_{3} \mathrm{~B} \cdot \mathrm{NMeH}_{2}(1 \mathrm{M}$, THF, $293 \mathrm{~K}$ ) varying $[\mathrm{Rh}]_{\text {Тот }}$ using 2 . Lines are of best fit in the pseudo-zero-order region. Dotted line represents 1 equiv of $\mathrm{H}_{2}$. (Inset A) $k_{\text {obs }}$ versus $[\mathrm{Rh}]_{\mathrm{TOT}}$ assuming $0.0019 \mathrm{M}$ trace water $(35 \mathrm{ppm})$. (Inset B) 0.125 mol $\%$ and $0.125 \mathrm{~mol} \%$ recharge at marked time.

suggest that for precatalyst $[\mathbf{1}] \mathbf{C l}$ the observed induction period allows for trace $\mathrm{H}_{2} \mathrm{O}$ to be reacted out with $\mathrm{H}_{3} \mathrm{~B}$. $\mathrm{NMeH}_{2}$ to form insoluble borates, possibly by catalytic hydrolysis. ${ }^{70}$ We cannot discount that such reactivity also helps activate the catalyst, as using stills-dried THF ( Na, $\sim 5$ ppm of $\mathrm{H}_{2} \mathrm{O}$ ) results in longer induction periods. ${ }^{71}$ The role of trace water in catalyst activation and speciation is well established. $^{72-75}$ Consistent with our hypothesis, using a loading of $0.125 \mathrm{~mol} \%(0.00125 \mathrm{M}, 2)$ that is lower than the trace contaminant results in an initial burst of catalysis followed by an effective halt-consistent with catalyst decomposition during turnover (inset B). Recharging with a further $0.125 \mathrm{~mol} \% 2$ restarted turnover, with a zero-order temporal profile and $k_{\mathrm{obs}}$ as measured for $0.25 \mathrm{~mol} \%$ [0.59(1) $\times 10^{-3} \mathrm{M} \mathrm{s}^{-1}$ ] in line with removal of $\sim 30 \mathrm{ppm}$ water.

Catalyst speciation studies ( $1 \mathrm{~mol} \%$, THF- $d_{8}$ ) showed the rapid formation of $3 / 3 \cdot \mathrm{H}_{3} \mathrm{BNMeH}_{2}$, being observed with 2 in a 0.85:0.15 ratio respectively during productive turnover, Figure 7A. At the end of catalysis (155 s) complex 2 is returned as the sole organometallic product. These data support a $\left[\mathrm{H}_{3} \mathrm{~B} \cdot \mathrm{NMeH}_{2}\right]$-dependent relationship between these species, that favors the ensemble of 3 as the dominant resting state $[2: 3=15: 85]$, and also confirms that the induction period observed with $[\mathbf{1}] \mathbf{C l}$ is due to its relatively slower consumption to give $\mathbf{2} / \mathbf{3}$. We return to this in Section 2.5 .

2.4. Isotope-Labeling Experiments and Eyring Analysis. The effect of isotopic substitution on the reaction profiles and speciation was probed using the isotopologues $\mathrm{H}_{3} \mathrm{~B}$. $\mathrm{NMeD}_{2}$ and $\mathrm{D}_{3} \mathrm{~B} \cdot \mathrm{NMeH}_{2}{ }^{29}$ and catalyst 2. $\mathrm{H}_{3} \mathrm{~B} \cdot \mathrm{NMeD}_{2}$ (Figure 7B) retained a zero-order profile for $\mathrm{H}_{2}$ evolution, albeit turnover was much slower and there is an apparent, subtle, induction phase. Using $\mathrm{D}_{3} \mathrm{~B} \cdot \mathrm{NMeH}_{2}$ (Figure $7 \mathrm{C}$ ) resulted in a significant deceleratory curvature, suggesting an isotopologue-dependent change in rate-determining step or catalyst speciation, as has been noted before. ${ }^{40}$ Compared with $\mathrm{H}_{3} \mathrm{~B} \cdot \mathrm{NMeH}_{2}$, speciation studies showed a progressive change in the position of the resting state using $\mathrm{D}_{3} \mathrm{~B} \cdot \mathrm{NMeH}_{2}$, that more rapidly moved to 2 , while for $\mathrm{H}_{3} \mathrm{~B} \cdot \mathrm{NMeD}_{2}$ the $2: 3$ ratio remains stable but even more in favor of 3 ( 5:95). Thus, the curvature observed using $\mathrm{D}_{3} \mathrm{~B} \cdot \mathrm{NMeH}_{2}$ supports the hypothesis 
(A) $\mathrm{H}_{3} \mathrm{~B} \cdot \mathrm{NMeH}_{2}$

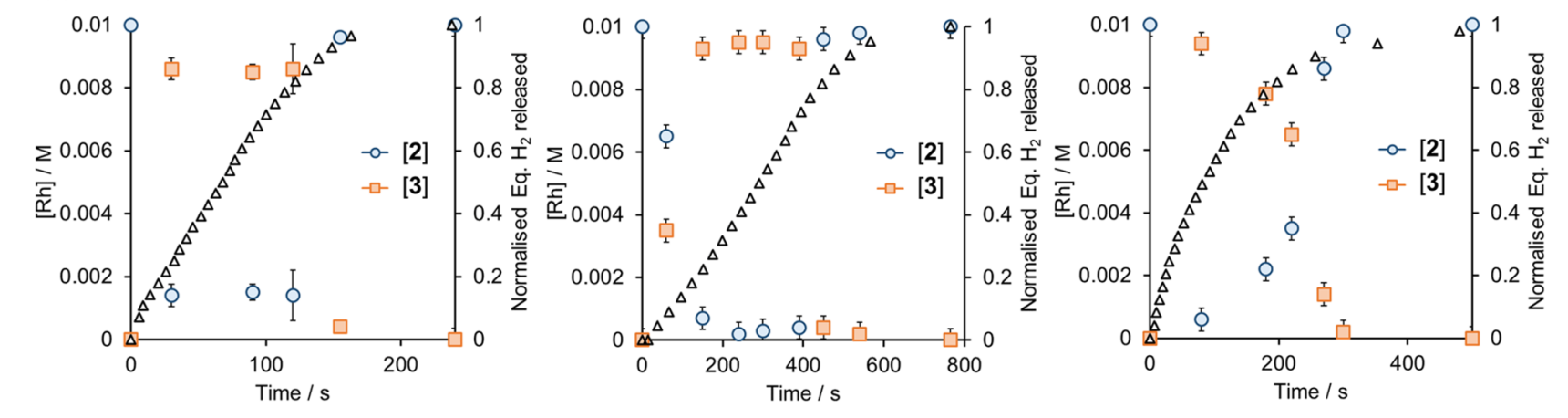

(B) $\mathrm{H}_{3} \mathrm{~B} \cdot \mathrm{NMeD}_{2}$

(B) $\mathrm{H}_{3} \mathrm{BNM}$

\section{(C) $\mathrm{D}_{3} \mathrm{~B} \cdot \mathrm{NMeH}_{2}$}

Figure 7. Temporal plots of speciation for catalyst 2 as measured using ${ }^{1} \mathrm{H},{ }^{31} \mathrm{P}\left\{{ }^{1} \mathrm{H}\right\}$ NMR spectroscopy at $185 \mathrm{~K}\left(1 \mathrm{~mol} \%\right.$, THF- $\left.d_{8}\right)$ and $\mathrm{H}_{2}$ evolution $\left(1 \mathrm{~mol} \%\right.$, THF- $d_{8}, 298 \mathrm{~K}$ ) using (A) $\mathrm{H}_{3} \mathrm{~B} \cdot \mathrm{NMeH}_{2}$, (B) $\mathrm{H}_{3} \mathrm{~B} \cdot \mathrm{NMeD}_{2}$, and (C) $\mathrm{D}_{3} \mathrm{~B} \cdot \mathrm{NMeH}_{2}$.

that 3 is the true catalyst while 2 sits off-cycle. By measuring the maximum rate at the early stages of catalysis, when 3 sits as the dominant $(85-95 \%)$ species, $k_{\text {Hobs }} / k_{\text {Dobs }}$ are estimated to be close to unity for $\mathrm{BH} / \mathrm{BD}, 1.5 \geq \mathrm{KIE} \geq 1.0$, and show a significant primary effect for $\mathrm{NH} / \mathrm{ND}, 3.3(2)$. While these values must be interpreted with caution given the changes in reaction profiles and speciation between 2 and 3 , especially with $\mathrm{D}_{3} \mathrm{~B} \cdot \mathrm{NMeH}_{2}$, they qualitatively support $\mathrm{N}-\mathrm{H}$ bond breaking being involved in the turnover determining manifold, while $\mathrm{B}-\mathrm{H}$ cleavage is not. Use of $[\mathbf{1}] \mathbf{C l}$ shows similar isotope effects, post observed induction period, which notably gets longer using $\mathrm{H}_{3} \mathrm{~B} \cdot \mathrm{NMeD}_{2}$. Deuterated polymer ${ }^{29}$ is formed in all cases (Table S7). ${ }^{76}$

By varying the temperature of dehydropolymerization between 288 and $303 \mathrm{~K}\left(0.5 \mathrm{~mol} \% 2, \mathrm{H}_{3} \mathrm{~B} \cdot \mathrm{NMeH}_{2}\right)$ a resulting Eyring analysis (Figure S6, using trace contaminant and speciation corrected [3]) leads to an estimation of the activation barriers: $\Delta H^{\ddagger}=16(2) \mathrm{kcal} \mathrm{mol}^{-1}, \Delta S^{\ddagger}=-5(8) \mathrm{cal}$ $\mathrm{K}^{-1} \mathrm{~mol}^{-1}$, and $\Delta G(298 \mathrm{~K})=17(3) \mathrm{kcal} \mathrm{mol}^{-1}$. There is very little change in isolated polymer using these different reaction temperatures $\left(M_{\mathrm{n}}=71000-81200 \mathrm{~g} \mathrm{~mol}^{-1}\right)$.

2.5. Mechanism of Dehydrogenation. The kinetics of $\mathrm{H}_{2}$ release, speciation studies, and isotope effects allow for a plausible mechanism for the dehydrogenation of $\mathrm{H}_{3} \mathrm{~B} \cdot \mathrm{NMeH}_{2}$ to be proposed and interrogated using computational methods. Before this is presented the likely processes that operate to connect $\mathbf{2}$ and $\mathbf{3}$ are briefly discussed.

That $\mathbf{2}$ and 3 are both observed during catalysis, their ratio during turnover is dependent on the isotopologue of $\mathrm{H}_{3} \mathrm{~B}$. $\mathrm{NMeH}_{2}$ used, and 3 reverts to 2 at low $\left[\mathrm{H}_{3} \mathrm{~B} \cdot \mathrm{NMeH}_{2}\right]$, shows they are connected by a finely balanced reaction network. We suggest this is as shown in Scheme 3. Informed by studies of Shubina ${ }^{68}$ and Beweries ${ }^{35}$ on the reaction of group-9 hydrido halides with $\mathrm{H}_{3} \mathrm{~B} \cdot \mathrm{NMe}_{2} \mathrm{H}$, or $\mathrm{H}_{3} \mathrm{~B} \cdot \mathrm{NMeH}_{2}$, that results in a close to ergo-neutral chloride/hydride metathesis; the conversion of 2 to 3 by $\mathrm{H}_{3} \mathrm{~B} \cdot \mathrm{NMeH}_{2}$ is proposed to proceed via transition state $\mathbf{B}$ to give 3 and $\mathrm{H}_{2} \mathrm{~B}=\mathrm{NMeH} /\left[\mathrm{NMeH}_{3}\right] \mathrm{Cl}$ in the presence of trace ${ }^{44} \mathrm{NMeH}_{2}$ that forms from $\mathrm{B}-\mathrm{N}$ bond cleavage in $\mathrm{H}_{3} \mathrm{~B} \cdot \mathrm{NMeH}_{2}$. These two coproducts would likely combine to afford the boronium chloride $\left[\mathrm{H}_{2} \mathrm{~B}\left(\mathrm{NMeH}_{2}\right)_{2}\right]$ $\mathrm{Cl}^{77}$ Stoichiometric reaction of in situ generated $3^{78}$ with $\left[\mathrm{H}_{2} \mathrm{~B}\left(\mathrm{NMe}_{2} \mathrm{H}\right)_{2}\right] \mathrm{Cl}^{79}$ in THF- $d_{8}$ results in the rapid (time of mixing) reformation of 2 alongside $\mathrm{HB}\left(\mathrm{NMe}_{2}\right)_{2}{ }^{80}$ and $\mathrm{H}_{2}$ (observed as bubbles). As the forward (2 to 3 ) and back (3 to 2) reactions involve $\mathrm{B}-\mathrm{H} / \mathrm{N}-\mathrm{H}$ and $\mathrm{N}-\mathrm{H}$ bond breaking respectively, the relative ratios of $\mathbf{2 : 3}$, as well as any observed induction periods, will be likely influenced by $\mathrm{H} / \mathrm{D}$

\section{Scheme 3. Interchange between 2 and 3}

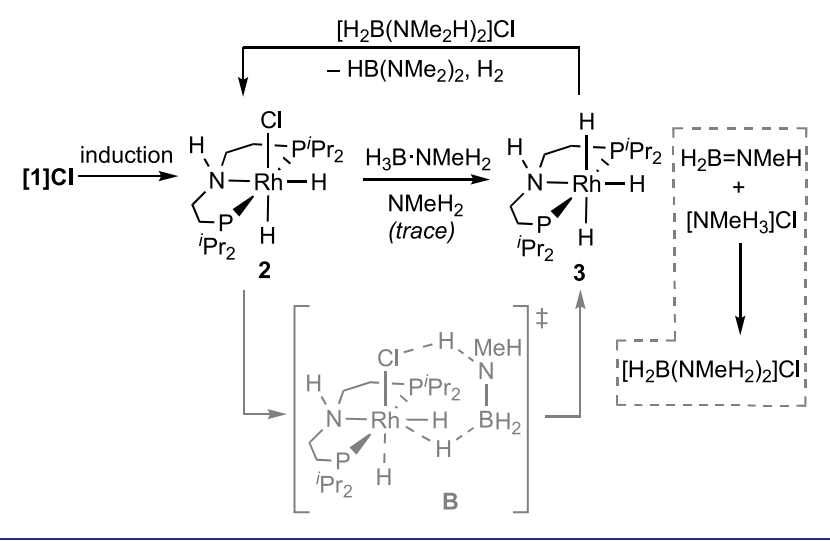

isotopologues of $\mathrm{H}_{3} \mathrm{~B} \cdot \mathrm{NMeH}_{2}$-as is observed in Figure 7 . In situ generated 3 (i.e., in the absence of boronium) is an active catalyst, turning over at rates very similar to precatalyst 2 $\left[0.5 \mathrm{~mol} \%, k_{\mathrm{obs}}=2.17(4) \times 10^{-3} \mathrm{M} \mathrm{s}^{-1}\right.$ and $2.59(5) \times 10^{-3} \mathrm{M}$ $\mathrm{s}^{-1}$ respectively].

Scheme 4 shows a proposed catalytic cycle that captures our observations, informed by computational studies (vide infra), and also builds upon work by Schneider and Beweries who invoke $\left.\mathrm{ML}_{n}\left\{\left({ }^{i} \mathrm{Pr}_{2} \mathrm{PCH}_{2} \mathrm{CH}_{2}\right)_{2} \mathrm{NH}\right)\right\}$ complexes as key intermediates $\left[\mathrm{ML}_{n}=\mathrm{RuH}_{2}\left(\mathrm{PMe}_{3}\right),{ }^{40} \mathrm{FeH}_{2} \mathrm{CO}^{27,39}\right]$ in amineborane dehydrogenation using the bifunctional PNHP ligand. Starting from 2 (itself coming from $[\mathbf{1}] \mathbf{C l}$ ), under conditions of high $\left[\mathrm{H}_{3} \mathrm{~B} \cdot \mathrm{NMeH}_{2}\right]$, resting state 3 rapidly forms, which sits as the outersphere adduct $3 \cdot \mathbf{H}_{3} \mathbf{B N M e H}$ (Figure 5). $\mathrm{N}-\mathrm{H}$ transfer to $\mathrm{Rh}-\mathrm{H}$ forms an amidoborane dihydrogen intermediate $C$, that undergoes $\mathrm{H}_{2}$ loss to give D. B-H hydride transfer and elimination of $\mathrm{H}_{2} \mathrm{~B}=\mathrm{NMeH}$ (see Section 2.6) returns 3 . This scheme captures the induction period starting for $[\mathbf{1}] \mathbf{C l}$, initial zero-order kinetics when starting from 2 (i.e., a resting state of $3 \cdot \mathbf{H}_{3} \mathbf{B N M e H}$ ), and the changes in resting state between 3 and 2 as $\mathrm{H}_{3} \mathrm{~B} \cdot \mathrm{NMeH}_{2}$ is consumed. As boronium $\left[\mathrm{H}_{2} \mathrm{~B}\left(\mathrm{NMeH}_{2}\right)_{2}\right] \mathrm{Cl}$ is suggested to be a coproduct in the formation of 3 from 2, and is also consumed to regenerate 2 , the ratio of $3:\left[\mathrm{H}_{2} \mathrm{~B}\left(\mathrm{NMeH}_{2}\right)_{2}\right] \mathrm{Cl}$ would be expected to remain constant. While off-cycle $\mathbf{2}$ is observed at low concentrations throughout, at the late stage of catalysis the back reaction with $\left[\mathrm{H}_{2} \mathrm{~B}\left(\mathrm{NMeH}_{2}\right)_{2}\right] \mathrm{Cl}$ becomes dominant, so that $\mathbf{2}$ is returned as the only organometallic product at the end. Doping 1 equiv $\left[\mathrm{H}_{2} \mathrm{~B}\left(\mathrm{NMe}_{2} \mathrm{H}\right)_{2}\right] \mathrm{Cl}$ at the start of catalysis $(2,1 \mathrm{~mol} \%)$ initially gives $3: 2$ in a ratio the same within error to the undoped experiments, but 2 becomes 


\section{Scheme 4. Proposed Catalytic Cycle}

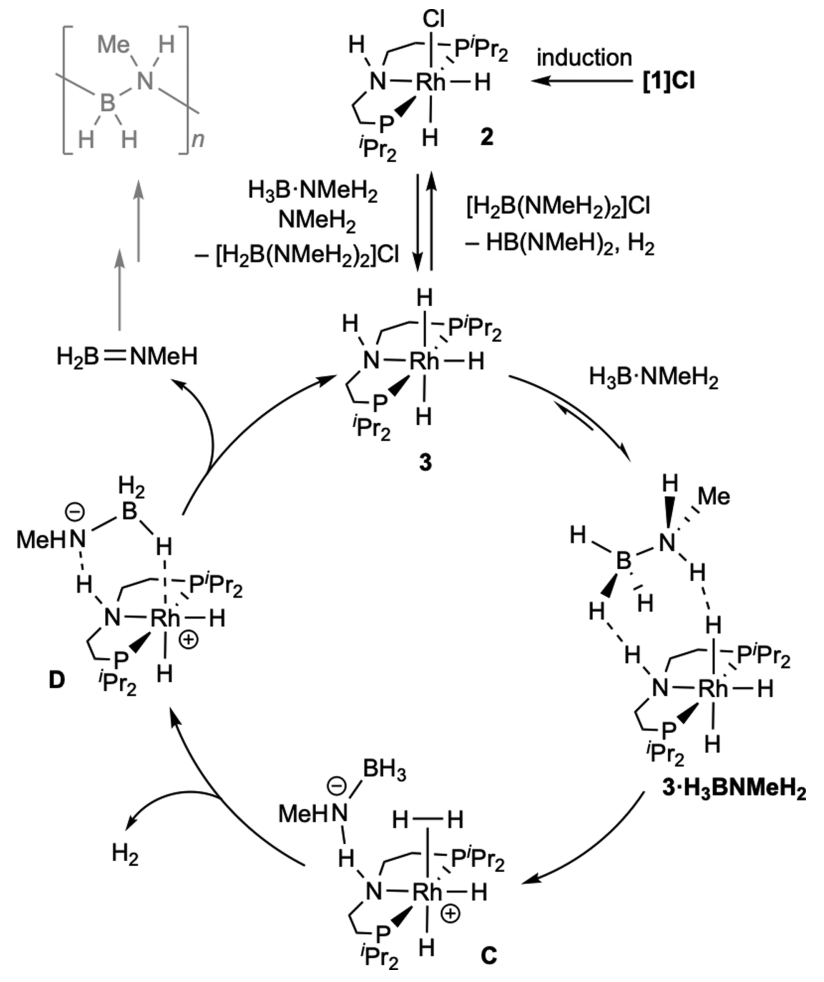

dominant earlier, at higher $\left[\mathrm{H}_{3} \mathrm{~B} \cdot \mathrm{NMeH}_{2}\right]$ (Figure S11). Initial rate measurements, on doped and undoped experiments, that probe the very early stages of catalysis, reflect this early speciation $\left[k_{\mathrm{obs}}=11.4(4) \times 10^{-3} \mathrm{M} \mathrm{s}^{-1}\right.$ and $11.7(6) \times 10^{-3} \mathrm{M}$ $\mathrm{s}^{-1}$, respectively]. Consistent with this observation $\left[\mathrm{H}_{2} \mathrm{~B}\right.$ $\left.\left(\mathrm{NMe}_{2} \mathrm{H}\right)_{2}\right] \mathrm{Cl}$ does not catalyze the dehydropolymerization of $\mathrm{H}_{3} \mathrm{~B} \cdot \mathrm{NMeH}_{2}$ under the conditions we use ( $1 \mathrm{~mol} \%$, THF, 1
M, $293 \mathrm{~K}),{ }^{81}$ while 3, or other neutral hydride catalysts such as $\left[\mathrm{Rh}(\mathrm{DPEphos}) \mathrm{H}_{2}\right]_{2},{ }^{44}$ are active catalysts when generated in the absence of boronium (vide supra). However, we cannot fully discount that added boronium plays a role in dehydropolymerization, in addition to chain transfer (Section 2.6 ), especially at the later stages of catalysis when $\mathbf{2}$ is dominant in the evolved reaction mixture. ${ }^{46,52,53}$

We propose that complex $\mathbf{3}$ is the actual catalyst, while $\mathbf{2}$ is dormant, as complex $\mathbf{2}$ is always observed with the $\mathrm{N}-\mathrm{H} / \mathrm{Rh}-$ $\mathrm{Cl}$ groups syn disposed, and so adducts such as $\mathbf{3} \cdot \mathbf{H}_{\mathbf{3}} \mathbf{B} \cdot \mathbf{N M e H}_{2}$, and thus intermediates such as $\mathbf{C}$, do not form. This may be due to the reaction between 3 and $\left[\mathrm{H}_{2} \mathrm{~B}\left(\mathrm{NMeH}_{2}\right)_{2}\right] \mathrm{Cl}$, that returns 2 , being templated by $\mathrm{Rh}-\mathrm{H} / \mathrm{N}-\mathrm{H}$ groups through nonclassical dihydrogen bonds. ${ }^{82}$

It was not possible to determine whether $\mathrm{D}$ is incorporated into the methylene backbone of the ligand when using $\mathrm{D}$ labeled amine-boranes, and thus whether an amine/amide ligand cooperative mechanism operates, ${ }^{83}$ as polymer signals obscured the aliphatic region of the ${ }^{1} \mathrm{H} /{ }^{2} \mathrm{H}$ NMR spectra. As isotope labeling experiments indicate that $\mathrm{N}-\mathrm{H}$ activation is involved either at, or in a preceding equilibrium with, the turnover limiting step DFT calculations were performed to clarify the details of the mechanism (see the Supporting Information for full details of the method used).

The computed free energy reaction profile for amine-borane dehydrogenation at 3 is shown in Scheme 5. Starting from adduct $\mathbf{3} \cdot \mathbf{H}_{3} \mathbf{B N M e H}_{2}$ (abbreviated to $\mathbf{3} \cdot \mathbf{A B}$ in Scheme 5 and in the ensuing discussion) an initial proton transfer from the amine-borane onto the hydride ligand syn to the ligand $\mathrm{N}-\mathrm{H}$ bond proceeds with a barrier of $14.7 \mathrm{kcal} \mathrm{mol}^{-1}$ to give Int(3. $\mathbf{A B}-\mathbf{C})$ at $+11.4 \mathrm{kcal} \mathrm{mol}^{-1}$. Int $(3 \cdot \mathbf{A B}-\mathbf{C})$ features a strong $\mathrm{H}$-bond between an amidoborane moiety and the ligand $\mathrm{N}-\mathrm{H}$ bond $(\mathrm{H} \cdots \mathrm{N}=1.50 \AA)$ and this corresponds to intermediate $\mathbf{C}$ in Scheme 4; however, prior to $\mathrm{H}_{2}$ dissociation a second

Scheme 5. Computed Free Energy Reaction Profile $\left(\mathrm{kcal} \mathrm{mol}^{-1}\right)$ for the Dehydrogenation of Amine-Borane Starting from Precursor Adduct $3 \cdot \mathrm{H}_{3} \mathrm{BNMeH}_{2}$ (Abbreviated to $\left.3 \cdot \mathrm{AB}\right)^{a}$

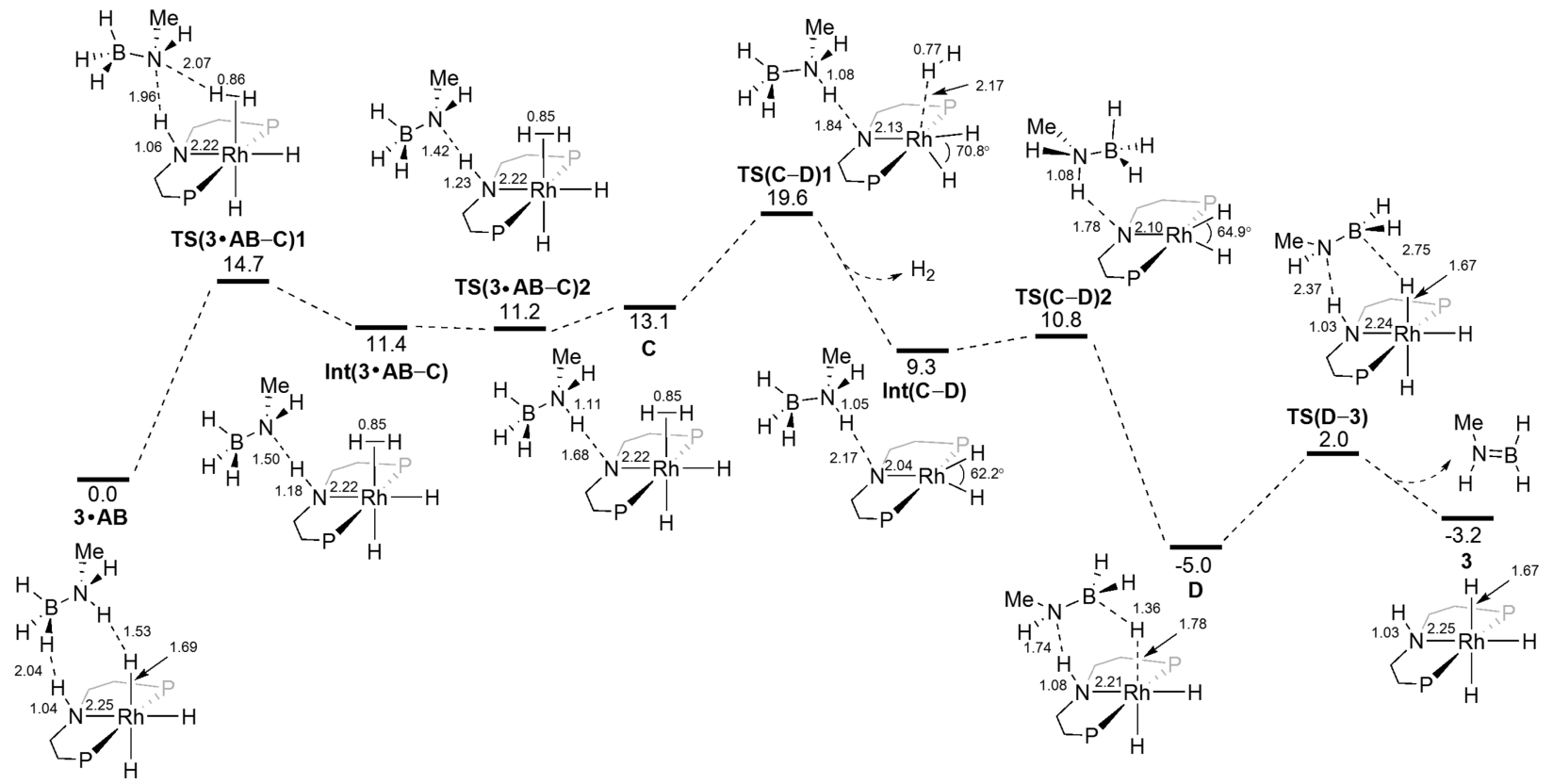

${ }^{a}$ Selected distances and angles are shown in $\AA$ and degrees; P = ${ }^{i} \operatorname{Pr}_{2}$. Level of theory: BP86[D3BJ,THF]/Def2TZVP//BP86/SDD (Rh, P, with polarization on $\mathrm{P}) ; 6-31 \mathrm{G}^{* *}$ on other atoms. 
proton transfer reforms $\mathrm{H}_{3} \mathrm{~B} \cdot \mathrm{NMeH}_{2}$ which is then $\mathrm{H}$-bonded to an amido group within the PNP ligand backbone. From here $\mathrm{H}_{2}$ dissociation proceeds via TS $(\mathbf{C}-\mathbf{D}) 1$ at $+19.6 \mathrm{kcal} /$ mol to form $\operatorname{Int}(\mathbf{C}-\mathbf{D})$. This species exhibits a distorted trigonal bipyramidal geometry with a very narrow $\mathrm{H}-\mathrm{Rh}-\mathrm{H}$ angle of $62.2^{\circ}$; such a Y-shaped arrangement of the equatorial (here $\mathrm{N}, \mathrm{H}, \mathrm{H}$ ) ligands is typical of a $\mathrm{d}^{6} \mathrm{M}(\mathrm{H})_{2} \mathrm{XL}_{2}$ species featuring a $\pi$-donor ligand, $\mathrm{X}^{84} \pi$-donors can labilize cis ligands, and amide ligands, as powerful $\pi$-donors, are among the most effective in this regard. ${ }^{85}$ Evidence that $\pi$-donation from the amido ligand assists $\mathrm{H}_{2}$ dissociation is seen in the progressive shortening of the $\mathrm{Rh}-\mathrm{N}$ distance as this proceeds (C: $2.22 \AA$; TS(C-D) 1: $2.13 \mathrm{~A}$; $\operatorname{Int}(\mathrm{C}-\mathrm{D}): 2.04 \AA)$ and the concomitant planarization of the amido $\mathrm{N}$ (sum of angles at $\mathrm{N}$ : C: $\left.330.2^{\circ} ; \operatorname{TS}(C-D) 1: 341.6^{\circ} ; \operatorname{Int}(C-D): 354.8^{\circ}\right)$. Access to this $\pi$-stabilization ${ }^{86}$ therefore explains the need for the additional proton transfer step between $\operatorname{Int}(3 \cdot \mathbf{A B}-\mathbf{C})$ and C. ${ }^{87}$ After $\mathrm{H}_{2}$ loss, facile rotation of the amine-borane moiety in $\operatorname{Int}(\mathbf{C}-\mathbf{D})$ forms $\mathbf{D}$ in which the $\mathrm{N}-\mathrm{H}$ proton has already transferred onto the amide $\mathrm{N}$ and one $\mathrm{B}-\mathrm{H}$ hydride is bridging the $\mathrm{B}$ and $\mathrm{Rh}$ centers $(\mathrm{B}-\mathrm{H}=1.36 \AA$; $\mathrm{Rh} \cdots \mathrm{H}=1.78 \AA$ ). The incipient aminoborane is therefore readily lost via $\mathrm{TS}(\mathrm{D}-3)$ at $+2.0 \mathrm{kcal} \mathrm{mol}^{-1}$ to form 3 that, upon adduct formation with another amine-borane substrate molecule, can restart the catalytic cycle. ${ }^{88}$

Scheme 5 indicates that amine-borane dehydrogenation proceeds with an overall barrier of $19.6 \mathrm{kcal} \mathrm{mol}^{-1}$, in good agreement with the experimentally determined value of 17(3) $\mathrm{kcal} \mathrm{mol}^{-1}$. The incipient loss of $\mathrm{H}_{2}$ in the turnoverdetermining transition is consistent with the close to zero experimentally measured entropy of activation. Dehydrogenation involves a pre-equilibrium featuring initial $\mathrm{N}-\mathrm{H}$ deprotonation of the amine-borane followed by rearrangement and rate-limiting $\mathrm{H}_{2}$ loss via TS(C-D)1. Rate constants derived from the barriers in Scheme 5 gave a computed $k \mathrm{H} / k \mathrm{D}$ value of 4.4, whereas a value of 1.0 was found when comparing $\mathrm{H}_{3} \mathrm{BNMeH}_{2}$ with $\mathrm{D}_{3} \mathrm{BNMeH}_{2}$ (see Supporting Information). This model compares well with the experimentally measured $k \mathrm{H}_{\text {obs }} / k \mathrm{D}_{\text {obs }}$.

2.6. Proposed Mechanism for Propagation and Chain Transfer. The consistent degree of polymerization, that is not significantly affected by catalyst loading, and relatively narrow dispersities measured for all polymer samples (Tables 1 and 2), point to a controlled, chain-growth, polymerization. Comparison with noncatalyzed systems, that generate $\mathrm{H}_{2} \mathrm{~B}=\mathrm{NMeH}$ in situ and show much broader dispersities ${ }^{31}$ or oligomer ${ }^{32}$ formation, suggests that the catalyst $\mathbf{3}$ also acts as an initiator in chain propagation, i.e., in a bifunctional role. ${ }^{18,40,44}$ As demonstrated, 3 is observed on cycle as the major species, moving to $\mathbf{2}$ at late stages, and the rate of generation of aminoborane scales, as measured by $\mathrm{H}_{2}$ evolution, positively with [3] (Figures 4 and $7 \mathrm{~A}$ ). We now extrapolate these observations to a plausible mechanism of chain growth and transfer, informed by prior computational studies on head-to-tail coupling of amino-boranes. $30,47,89$

Scheme 6A shows the proposed initiation step for polymerization, by the formation of a pendant amidoborohydride, $^{90}$ E, through coordination of $\mathrm{H}_{2} \mathrm{~B}=\mathrm{NMeH}$ with 3 . This develops a lone pair on $\mathrm{N}$, which then undergoes a head-to-tail $\mathrm{B}-\mathrm{N}$ bond forming event with a subsequent equivalent of $\mathrm{H}_{2} \mathrm{~B}=\mathrm{NMeH}$. Repeating this process propagates a polymer chain from the $\mathrm{Rh}$ center, $\mathbf{F}$, as shown computationally to be a very low barrier process for catalyst/initiator
Scheme 6. Proposed Chain Propagation (A); Catalyst/ Initiator Regeneration (B); Chain Transfer (C)

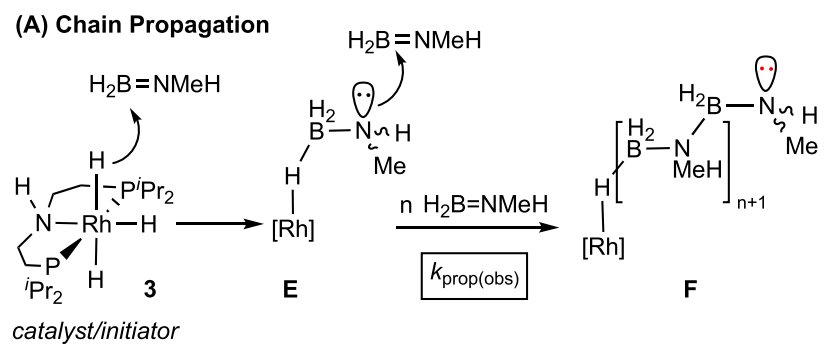

(B) Catalyst/Initiator Regeneration/Consumption
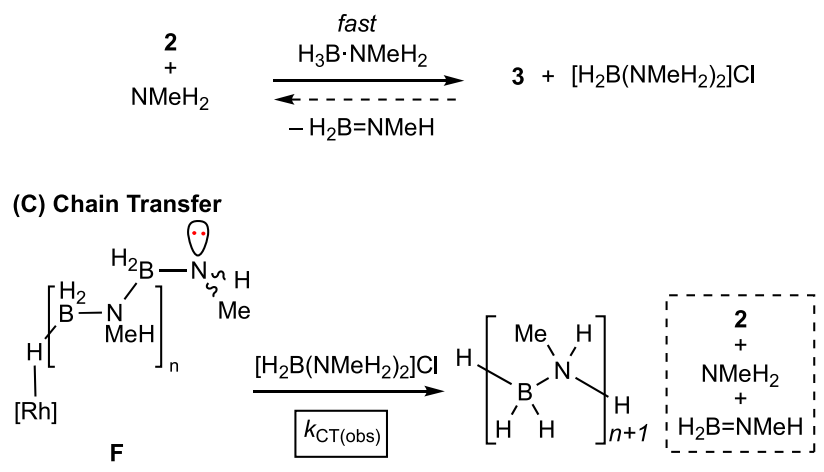

$\mathbf{A}^{47}$ or stoichiometric amine initiators. ${ }^{30}$ As premonomer $\mathrm{H}_{3} \mathrm{~B}$. $\mathrm{NMeH}_{2}$ is necessary for both the formation of $\mathbf{3}$ (Scheme 4) and the generation, mediated by 3 , of the actual monomer, $\mathrm{H}_{2} \mathrm{~B}=\mathrm{NMeH}$, (Scheme 6B) the (catalyst/initiator):monomer ratio might be expected to remain constant. As signaled by narrow dispersities of isolated polymer, chain transfer processes are also geared with propagation. By invoking boronium, $\left[\mathrm{H}_{2} \mathrm{~B}\left(\mathrm{NMeH}_{2}\right)_{2}\right] \mathrm{Cl}$ as a chain transfer agent (Scheme 6C), as previously shown for the $\left.\mathrm{Rh}(\mathrm{DPEphos}) \mathrm{H}_{2}\right]_{2}$ catalyst system, ${ }^{44}$ this requirement is satisfied, if $\mathbf{2}$ is also reformed in this process. This is due to $\left[\mathrm{H}_{2} \mathrm{~B}\left(\mathrm{NMeH}_{2}\right)_{2}\right] \mathrm{Cl}$ being regenerated as a coproduct alongside 3 and thus its concentration will also be controlled by $\left[\mathrm{H}_{3} \mathrm{~B} \cdot \mathrm{NMeH}_{2}\right]$. While the zero-order kinetics simplify any analysis somewhat, our general hypothesis is that this cascade polymerization is precisely geared around the concentration of premonomer $\mathrm{H}_{3} \mathrm{~B} \cdot \mathrm{NMeH}_{2}$, and thus $k_{\text {prop(obs) }} / k_{\mathrm{CT}(\mathrm{obs})}$ remains relatively unchanged throughout catalysis-leading to a consistent degree of polymerization and relatively narrow dispersities.

Support for this hypothesis comes from increasing the relative concentration of chain-transfer agent and its effect on the degree of polymerization. Conveniently synthesized $\left[\mathrm{H}_{2} \mathrm{~B}\left(\mathrm{NMe}_{2} \mathrm{H}\right)_{2}\right] \mathrm{Cl}^{79}$ was used for this, and the reaction was performed under conditions where no special precautions were taken for the ingress of air. Doping in 0-2 equiv (per [Rh]) of $\left[\mathrm{H}_{2} \mathrm{~B}\left(\mathrm{NMe}_{2} \mathrm{H}\right)_{2}\right] \mathrm{Cl}$ with $[\mathbf{1}] \mathrm{Cl}\left(0.5 \mathrm{~mol} \%, 1 \mathrm{M} \mathrm{H}_{3} \mathrm{~B} \cdot \mathrm{NMeH}_{2}\right)$ showed a progressive shortening of the isolated polymer (68500 $\mathrm{g} \mathrm{mol}^{-1}$ to $37900 \mathrm{~g} \mathrm{~mol}^{-1}$ respectively), while dispersities remained relatively narrow (1.6-1.8). Polymer yield and selectivity remained excellent (Table S9). Figure 8 shows a resulting Mayo-type analysis of added [boronium]/ $\left[\mathrm{H}_{3} \mathrm{~B} \cdot \mathrm{NMeH}_{2}\right]$ versus $1 / M_{\mathrm{n}}$ that strongly supports boronium acting as a chain transfer agent.

2.7. Practical Synthesis of Polyaminoborane on $10 \mathrm{~g}$ Scale at $0.01 \mathrm{~mol} \%$ (12 ppm) Catalyst Loadings. With a robust, controlled, polymerization system in hand we 


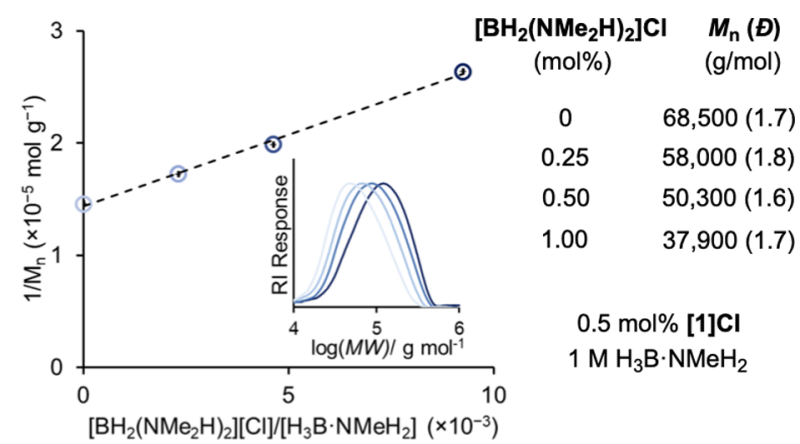

Figure 8. Mayo analysis of added boronium doping. Inset shows overlaid GPC traces of isolated polymer samples.

investigated scaling up to useful amounts for materials processing applications $(10 \mathrm{~g})$. Using $[\mathbf{1}] \mathbf{C l}$ at $0.01 \mathrm{~mol} \%$ loading and high concentrations of $\left[\mathrm{H}_{3} \mathrm{~B} \cdot \mathrm{NMeH}_{2}\right](5 \mathrm{M}, 45$ $\mathrm{cm}^{3}$ THF) dehydropolymerization can be carried out in a beaker without any precautions for ingress of air (Figure 9) on a synthetically useful time scale ( $2 \mathrm{~h}$, unoptimized). The Supporting Information (Movie S2) shows this process in more detail.

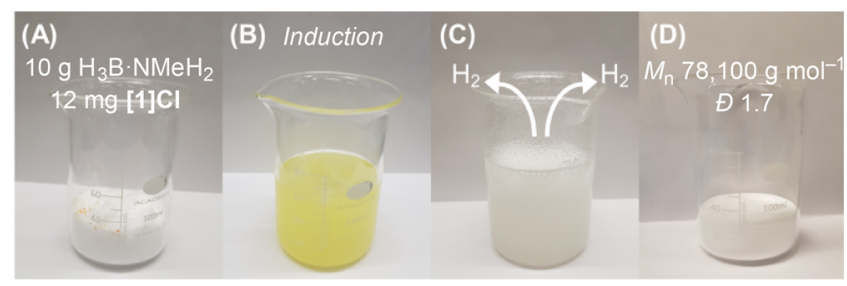

Figure 9. Air-tolerant dehydropolymerization. (A) $10 \mathrm{~g} \mathrm{H}_{3} \mathrm{~B} \cdot \mathrm{NMeH}_{2}$ and $12 \mathrm{mg}(12 \mathrm{ppm})$ [1]Cl. (B) $45 \mathrm{~cm}^{3}$ THF (induction period $\sim 10$ min). (C) $\mathrm{H}_{2}$ evolution. (D) Isolated polymer after precipitation (pentane) and drying ( 9.3 g).

The polyaminoborane formed is of high molecular weight, similar to that obtained on smaller scales (Tables 1 and 2), with high yield (97\%), selectivity (98\%, by ${ }^{11} \mathrm{~B}$ NMR spectroscopy), and relatively narrow dispersity with a symmetrical molecular weight distribution: $M_{\mathrm{n}}=78100 \mathrm{~g} \mathrm{~mol}^{-1}$, $Ð=1.7$. Reproducibility was shown over three separate batches (Table S10, Figure S12). Chain control using boronium was also possible on this $10 \mathrm{~g}$ scale. Addition of 1 mol \% $\left[\mathrm{H}_{2} \mathrm{~B}\left(\mathrm{NMe}_{2} \mathrm{H}\right)_{2}\right] \mathrm{Cl}$ to a large scale dehydropolymerization $(0.01 \mathrm{~mol} \%[\mathbf{1}] \mathbf{C l})$ produced polyaminoborane selectively (99\%) and in high isolated yield (93\%) but at considerably shorter degrees of polymerization, $M_{\mathrm{n}}=24000 \mathrm{~g}$ $\mathrm{mol}^{-1}, Ð=1.7$.

2.8. Materials Characterization. In addition to GPC and NMR spectroscopic characterization, polyaminoborane samples of varying molecular weight were analyzed by DSC and TGA thermal analysis, Table 3: coming from eudiometric studies (entries 1-2), open vial boronium doping (entries 36 ), and different concentrations/large scale syntheses (entries 7 and 8). These data provide information on polymer physical properties that can then be applied in polymer processing, i.e., glass transition temperature $\left(T_{\mathrm{g}}\right)$ and the temperature of polymer decomposition $\left(T_{\mathrm{dec}}\right)$.

The thermal mass loss (TGA) behavior of all polymer samples can be characterized by two events, for which Figure $10 \mathrm{~A}$ presents a representative trace. First is a minor mass loss
Table 3. Thermal Analysis of Polymer Samples

\begin{tabular}{cccccc} 
entry & $\begin{array}{c}{[\mathrm{Rh}]_{\mathrm{TOT}}} \\
(\mathrm{mol} \mathrm{\% )}\end{array}$ & $\begin{array}{c}M_{\mathrm{n}}{ }^{e} \\
\left(\mathrm{~g} \mathrm{~mol}^{-1}\right)\end{array}$ & $\begin{array}{c}T_{\mathrm{g}}^{f} \\
\left({ }^{\circ} \mathrm{C}\right)\end{array}$ & $\begin{array}{c}T_{\mathrm{dec}}{ }^{g}\left({ }^{\circ} \mathrm{C}\right) \\
(\text { wt \%) }\end{array}$ & $\begin{array}{c}\text { ceramic yield }^{h} \\
(\%)\end{array}$ \\
\hline 1 & $0.25^{a}$ & 74600 & 72 & $165(15)$ & 62 \\
2 & $1.00^{a}$ & 71200 & 70 & $159(28)$ & 52 \\
3 & $0.5^{b}$ & 68500 & 103 & $163(60)$ & 29 \\
4 & $0.5^{b}$ & 58000 & 95 & $160(59)$ & 33 \\
5 & $0.5^{b}$ & 50300 & 92 & $158(59)$ & 30 \\
6 & $0.5^{b}$ & 37900 & 87 & $157(46)$ & 34 \\
7 & $0.5^{c}$ & 61300 & 106 & $158(58)$ & 29 \\
8 & $0.01^{d}$ & 78100 & 54 & $163(83)$ & 9
\end{tabular}

${ }^{a}$ Eudiometer conditions. ${ }^{b}$ Open vial, $1 \mathrm{M}\left[\mathrm{H}_{3} \mathrm{~B} \cdot \mathrm{NMeH}_{2}\right]$, boronium doping experiments, see Figure 8 for details. ${ }^{c}$ Open vial, $5 \mathrm{M}\left[\mathrm{H}_{3} \mathrm{~B}\right.$. $\left.\mathrm{NMeH}_{2}\right]$. ${ }^{d}$ Open beaker, $10 \mathrm{~g}$ scale, $5 \mathrm{M}\left[\mathrm{H}_{3} \mathrm{~B} \cdot \mathrm{NMeH}_{2}\right]$, representative example from three consistent batches, see Table S10. ${ }^{e}$ Relative to polystyrene standards. ${ }^{f}$ Ramp $10{ }^{\circ} \mathrm{C} / \mathrm{min}$. ${ }^{g}$ Temperature of major mass loss event from peak maxima in derivative thermogram (mass loss \%). ${ }^{h_{1}}$ Sample mass (wt \%) remaining after heating to $500{ }^{\circ} \mathrm{C}$.

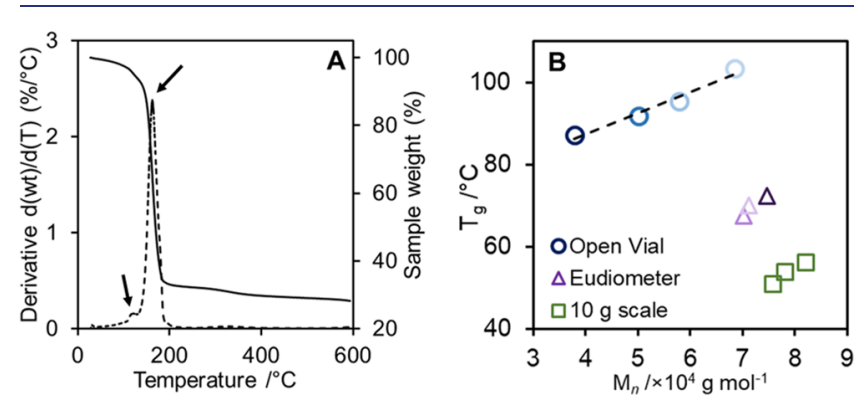

Figure 10. Thermal characterization of polymers. (A) Typical thermal degradation showing mass loss (solid line) and decomposition events (derivative weight; dashed line, arrows highlighting the maxima). (B) Relationship between degree of polymerization $\left(\mathrm{M}_{n}\right)$ with $T_{\mathrm{g}}$ and $T_{\text {decomp }}$ (major decomp. event). See Tables 3, S13, S15 for data.

between $100-117^{\circ} \mathrm{C}$, corresponding to $1-6 \%$ sample weight and is most likely due to entrained solvent (THF) loss from the polymer matrix. Consistent with this, THF is observed by ${ }^{1} \mathrm{H}$ NMR spectroscopy of isolated polymer, even after extended drying under a vacuum (Figure S47). However, a contribution from hydrogen loss ( 1 equiv $\mathrm{H}_{2}$ loss is $4.9 \mathrm{wt} \%$ loss) from polyaminoboranes cannot be discounted. The major

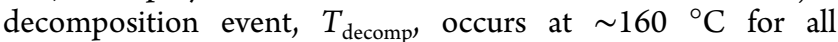
samples, varying over only a small temperature range of $8{ }^{\circ} \mathrm{C}$, and was determined by inspection of the derivative trace. These are in the range previously reported for $\left(\mathrm{H}_{2} \mathrm{BNMeH}_{2}\right)_{n}$ : 134- $160{ }^{\circ} \mathrm{C} .^{15,18,29}$

The $T_{\mathrm{g}}$, however, are more sensitive to both the degree of polymerization and the sample preparation method, Figure 10B, Table 3. Within self-consistent sets of samples (eudiometric, open vial, $10 \mathrm{~g}$ scale), each set shows a linear relationship between $T_{\mathrm{g}}$ and $M_{\mathrm{n}}$, albeit over a small absolute temperature range $\left(16{ }^{\circ} \mathrm{C}\right)$. Open vial conditions with boronium doping produce polymer with higher $T_{\mathrm{g}}$ (87-103 $\left.{ }^{\circ} \mathrm{C}\right)$, eudiometric conditions lower $\left(70-72{ }^{\circ} \mathrm{C}\right)$ and large scale, $10 \mathrm{~g}$, even lower $\left(54-56^{\circ} \mathrm{C}\right)$. Concentration $(1 \mathrm{M}$ and $5 \mathrm{M})$ and temperature $\left(15\right.$ to $30{ }^{\circ} \mathrm{C}$ ) do not have a significant effect on $T_{\mathrm{g}}$ (Tables S14 and S16). Ceramic yields (measured to 500 ${ }^{\circ} \mathrm{C}$ ) are also dependent on polymer synthesis conditions (Table 3) but are not correlated with $T_{\mathrm{g}}$ and range widely from $62 \%$ to $9 \%$. A more systematic study based on a wider range of samples/methods is undoubtably needed as the field moves 
forward to fully establish correlations between material properties, polymer structure, and synthesis methods. It is well-established that differences in reaction vessel shape can also have significant effects on reactivity. ${ }^{91,92}$ Given $\mathrm{H}_{2}$ degassing is vigorous for all preparation methods (Movies S1 and S2), surface area effects, that are controlled by the shape of the reaction vessel, may be important in influencing the amount of polymer entanglement-which would in turn control $T_{\mathrm{g}}$. Entrained catalyst or boronium may also result in different $T_{\mathrm{g}}$.

Whatever the drivers behind the differences in $T_{\mathrm{g}}$ and the temperature of decomposition, the polymer samples that show the largest differential between these two parameters are those prepared on the largest scale, $10 \mathrm{~g}$, which provide a potential melt processing window of between 54 and $163{ }^{\circ} \mathrm{C}$. The processing of these materials is discussed next.

2.9. Processing. Material processing techniques were briefly explored using polymer solutions or the molten state, and are exemplified by melt extruding, drop casting, ${ }^{41}$ and electrospray deposition ${ }^{2}$ (Figure 11).

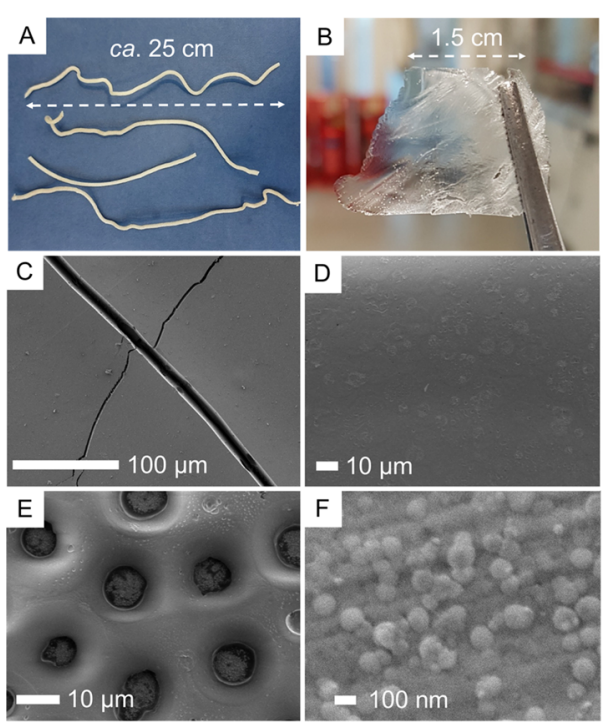

Figure 11. Examples of processed polyaminoborane. (A) Meltextruded. (B) Drop-cast thin film. (C) SEM image of drop-cast thin film. (D) Electrosprayed thin film SEM image. (E) Porous film SEM image. (F) Polymer beads SEM image.

A sample of polyaminoborane $\left(M_{\mathrm{n}}=82100 \mathrm{~g} \mathrm{~mol}^{-1}, T_{\mathrm{g}} 56\right.$ ${ }^{\circ} \mathrm{C}$ ) was melt extruded at $100{ }^{\circ} \mathrm{C}$ to yield long strands (Figure 11A) of a very brittle material (i.e., breaks to the touch). GPC analysis of this extruded material supports retention of the degree of polymerization in the bulk sample $\left(M_{\mathrm{n}}=76300 \mathrm{~g}\right.$ $\left.\mathrm{mol}^{-1}, \oplus 1.7\right)$. While solution state NMR spectra $\left(\mathrm{CDCl}_{3}\right)$ revealed small amounts $(\sim 5 \%)$ of low molecular weight, decomposition products, by relatively sharp signals being observed for $\left[\mathrm{H}_{2} \mathrm{BNMeH}\right]_{3}{ }^{20}$ and $\mathrm{H}_{3} \mathrm{BNMeHBH}_{2} \mathrm{NMeH}_{2}$, ${ }^{93}$ the bulk of the sample remained polyaminoborane (Figure S56). Powder X-ray diffraction (PXRD) experiments showed this processed/extruded material to be semicrystalline with a $d$ spacing of the two main peaks at approximately 5.8 and $4.2 \AA$ (Figure S58). Small Angle X-ray Scattering (SAXS) data could be modeled as a distribution of hard spheres, for which there is also evidence of nonseparation. As a result of this an interaction term was included, giving a mean radius of 2.5 $\mathrm{nm}$ for these spheres. ${ }^{94}$ The inclusion of this term suggests the particles/domains have a degree of ordering in the extruded material. Attempts to hot press films also resulted in a very brittle material. The resulting SAXS data was modeled as hard spheres of radii of 7.2 and $6.4 \mathrm{~nm}$, with scattering from nanomaterial, and an interaction term was not needed. PXRD measurements on these hot-pressed materials showed they were also semicrystalline, with a similar $d$-spacing of 6.1 and 4.4 A, slightly different from the extruded samples. Effects arising from the curvature of the extruded strand could contribute to this small observed difference in $d$-spacing.

Room temperature drop-casting of a concentrated $(\sim 5 \mathrm{M}$, THF) sample produced a clear, colorless, film of polyaminoborane upon solvent evaporation (Figure 11B). This drop-cast film underwent solvent-induced crazing when manipulated (Figure 11C). ${ }^{95}$ SEM images of the surface of this film show a discontinuous macrostructure of closely packed spheres with diameter $<50 \mathrm{~nm}$ (Figure S53).

Thin $(<1 \mu \mathrm{m})$, smooth films of polyaminoborane (Figure 11D) were successfully produced through electrospray deposition (10-35 $\left.\mathrm{min}, 1.8 \mathrm{~mL} \mathrm{~h}^{-1}, 7-9 \mathrm{keV}\right)$ from solution in THF $(\sim 0.5 \mathrm{M})$ using a vertical set up. Shorter deposition time $(<5 \mathrm{~min})$ promoted the self-assembly of a regular, porous microstructure (Figure 11E) through rapid solvent evaporation. ${ }^{96}$ The pores $(\sim 10 \mu \mathrm{m}$ diameter $)$ in these membranelike structures were confirmed to penetrate the full film depth using EDS spectroscopy (Figure S52). Finally, use of a horizontal electrospray setup with high applied voltage (30 $\mathrm{keV}$ ) to destabilize the cone jet, $0.4 \mathrm{M}$ polymer in 60:40 DMF:THF and short deposition times $\left(<5 \mathrm{~min}\right.$ at $\left.3 \mathrm{~mL} \mathrm{~h}^{-1}\right)$ yields regular, spherical beads $(\sim 100 \mathrm{~nm}$ diameter $)$ of polyaminoborane (Figure 11F).

\section{CONCLUSIONS}

We report here a reliable, scalable, conveniently synthesized, and air-tolerant catalyst system, $[\mathbf{1}] \mathbf{C l}$, for the dehydropolymerization of $\mathrm{H}_{3} \mathrm{~B} \cdot \mathrm{NMeH}_{2}$ to selectively form $\mathrm{N}$-methyl polyaminoborane, $\left(\mathrm{H}_{2} \mathrm{BNMeH}\right)_{n}$. This system works at low catalyst loadings $(0.01 \mathrm{~mol} \%)$ to produce well-defined polymers with relatively narrow dispersity, and chain length control has been demonstrated using boronium $\left[\mathrm{H}_{2} \mathrm{~B}\right.$ $\left.\left(\mathrm{NMe}_{2} \mathrm{H}\right)_{2}\right] \mathrm{Cl}$ as a chain-transfer agent. Upon the basis of our detailed mechanistic studies, we propose that this selective, controlled, cascade polymerization results from an ensemble of processes (catalyst speciation, dehydrogenation, propagation, and chain transfer) that are all geared around the concentration of $\mathrm{H}_{3} \mathrm{~B} \cdot \mathrm{NMeH}_{2}$. We suggest it is likely that similar correlated processes are operating with catalysts that also mediate controlled dehydropolymerization, ${ }^{25,28,37,41,44}$ although the precise mechanistic details will likely differ between specific examples.

Leveraging these desirable attributes of the catalyst system [1] Cl allows for the straightforward preparation of $\left(\mathrm{H}_{2} \mathrm{BNMeH}\right)_{n}$ on a scale $(10 \mathrm{~g})$ that allows for the nascent materials properties of polyaminoboranes to be systematically investigated, building upon previously reported examples. $^{15,16,18,19}$ The variety of processing methods used (melt extrusion, drop casting, and electrospraying) suggests that polyaminoboranes offer significant opportunities in materials chemistry, and given that $[\mathbf{1}] \mathbf{C l}$ is a straightforward to prepare catalyst, there should be no significant impediment to its wider deployment for the synthesis of polyaminoboranes. It will be interesting to see if catalysts based on $[\mathbf{1}] \mathbf{C l}$ can mediate the dehydropolymerization of more functionalized amine-bor- 
anes, ${ }^{27,31,37}$ that may offer polymers with tuned materials properties compared to $\left(\mathrm{H}_{2} \mathrm{BNMeH}\right)_{n}$.

\section{ASSOCIATED CONTENT}

\section{SI Supporting Information}

The Supporting Information is available free of charge at https://pubs.acs.org/doi/10.1021/jacs.1c10888.

Full details of experimental and characterization data for the new complexes, kinetics data, materials data collection, and computational studies (PDF)

Coordinates of computed intermediates and transition states (XYZ)

Movie S1: Representative eudiometric analysis using $\mathbf{1}[\mathbf{C l}](\mathrm{MOV})$

Movie S2: Representative 10 g-scale polymer synthesis using $\mathbf{1}[\mathbf{C l}](\mathrm{MOV})$

\section{Accession Codes}

CCDC 2115101-2115102 contain the supplementary crystallographic data for this paper. These data can be obtained free of charge via www.ccdc.cam.ac.uk/data_request/cif, or by emailing data_request@ccdc.cam.ac.uk, or by contacting The Cambridge Crystallographic Data Centre, 12 Union Road, Cambridge CB2 1EZ, UK; fax: +44 1223336033.

\section{AUTHOR INFORMATION}

\section{Corresponding Authors}

David M. Haddleton - Department of Chemistry, University of Warwick, Coventry CV4 7AL, U.K.; ○ orcid.org/00000002-4965-0827; Email: d.m.haddleton@warwick.ac.uk

Stuart A. Macgregor - Institute of Chemical Sciences, HeriotWatt University, Edinburgh EH14 4AS, U.K.; 이이이.org/ 0000-0003-3454-6776; Email: s.a.macgregor@hw.ac.uk

Andrew S. Weller - Department of Chemistry, University of York, Heslington, York YO31 1ES, U.K.; @ orcid.org/00000003-1646-8081; Email: andrew.weller@york.ac.uk

\section{Authors}

Claire N. Brodie - Department of Chemistry, University of York, Heslington, York YO31 1ES, U.K.; O orcid.org/00000002-8896-0270

Timothy M. Boyd - Department of Chemistry, University of York, Heslington, York YO31 1ES, U.K.; Department of Chemistry, University of Oxford, Oxford OX1 3TA, U.K.; (1) orcid.org/0000-0001-6607-3761

Lia Sotorríos - Institute of Chemical Sciences, Heriot-Watt University, Edinburgh EH14 4AS, U.K.

David E. Ryan - Department of Chemistry, University of York, Heslington, York YO31 1ES, U.K.; Department of Chemistry, University of Oxford, Oxford OX1 3TA, U.K.; (1) orcid.org/ 0000-0001-8381-9502

Eimear Magee - International Institute for Nanocomposites Manufacturing, WMG, University of Warwick, Coventry CV4 7AL, U.K.

Steven Huband - Department of Physics, University of Warwick, Coventry CV4 7AL, U.K.

James S. Town - Department of Chemistry, University of Warwick, Coventry CV4 7AL, U.K.

Guy C. Lloyd-Jones - School of Chemistry, University of Edinburgh, Edinburgh EH9 3FJ Scotland, U.K.; (1) orcid.org/0000-0003-2128-6864

Complete contact information is available at: https://pubs.acs.org/10.1021/jacs.1c10888

\section{Author Contributions}

${ }^{\mathrm{II}}$ C.N.B. and T.M.B. contributed equally.

Notes

The authors declare no competing financial interest.

\section{ACKNOWLEDGMENTS}

EPSRC (EP/M024210/2; EP/T019867/1), University of Oxford. Drs R. Douthwaite and C. Spicer (York) for help with electrospray experiments. The York Jeol Nanocentre.

\section{REFERENCES}

(1) Staubitz, A.; Robertson, A. P. M.; Sloan, M. E.; Manners, I. Amine- and Phosphine-Borane Adducts: New Interest in Old Molecules. Chem. Rev. 2010, 110, 4023-4078.

(2) Leitao, E. M.; Jurca, T.; Manners, I. Catalysis in Service of Main Group Chemistry Offers a Versatile Approach to P-Block Molecules and Materials. Nat. Chem. 2013, 5, 817-829.

(3) Vidal, F.; Jäkle, F. Functional Polymeric Materials Based on Main-Group Elements. Angew. Chem., Int. Ed. 2019, 58, 5846-5870.

(4) Colebatch, A. L.; Weller, A. S. Amine-Borane Dehydropolymerization: Challenges and Opportunities. Chem. - Eur. J. 2019, 25, 1379-1390.

(5) Sauter, D. W.; Taoufik, M.; Boisson, C. Polyolefins, a Success Story. Polymers 2017, 9, 185-198.

(6) Hartwig, J. F. Organotransition Metal Chemistry. From Bonding to Catalysis; University Science Books: Sausalito, 2010.

(7) Chen, E. Y. X. Coordination Polymerization of Polar Vinyl Monomers by Single-Site Metal Catalysts. Chem. Rev. 2009, 109, $5157-5214$

(8) Ittel, S. D.; Johnson, L. K.; Brookhart, M. Late-Metal Catalysts for Ethylene Homo- and Copolymerization. Chem. Rev. 2000, 100, 1169-1204

(9) Chen, C. Designing Catalysts for Olefin Polymerization and Copolymerization: Beyond Electronic and Steric Tuning. Nature. Rev. Chem. 2018, 2, 6-14.

(10) Komm, R.; Geanangel, R. A.; Liepins, R. Synthesis and Studies of Poly(Aminoborane), $\left(\mathrm{H}_{2} \mathrm{NBH}_{2}\right)_{\mathrm{X}}$. Inorg. Chem. 1983, 22, 16841686.

(11) Priegert, A. M.; Rawe, B. W.; Serin, S. C.; Gates, D. P. Polymers and the P-Block Elements. Chem. Soc. Rev. 2016, 45, 922-953.

(12) Nakhmanson, S. M.; Nardelli, M. B.; Bernholc, J. Ab Initio Studies of Polarization and Piezoelectricity in Vinylidene Fluoride and BN-Based Polymers. Phys. Rev. Lett. 2004, 92, 115504.

(13) Zhang, Y.; Hopkins, M. A.; Liptrot, D. J.; Khanbareh, H.; Groen, P.; Zhou, X.; Zhang, D.; Bao, Y.; Zhou, K.; Bowen, C. R.; et al. Harnessing Plasticity in an Amine-Borane as a Piezoelectric and Pyroelectric Flexible Film. Angew. Chem., Int. Ed. 2020, 59, 78087812.

(14) Bernard, S.; Miele, P. Polymer-Derived Boron Nitride: A Review on the Chemistry, Shaping and Ceramic Conversion of Borazine Derivatives. Materials 2014, 7, 7436-7459.

(15) Du, V. A.; Jurca, T.; Whittell, G. R.; Manners, I. Aluminum Borate Nanowires from the Pyrolysis of Polyaminoborane Precursors. Dalton Trans. 2016, 45, 1055-1062.

(16) Wang, X.; Hooper, T. N.; Kumar, A.; Priest, I. K.; Sheng, Y.; Samuels, T. O. M.; Wang, S.; Robertson, A. W.; Pacios, M.; Bhaskaran, H.; et al. Oligomeric Aminoborane Precursors for the Chemical Vapour Deposition Growth of Few-Layer Hexagonal Boron Nitride. CrystEngComm 2017, 19, 285-294.

(17) Dietrich, B. L.; Goldberg, K. I.; Heinekey, D. M.; Autrey, T.; Linehan, J. C. Iridium-Catalyzed Dehydrogenation of Substituted Amine Boranes: Kinetics, Thermodynamics, and Implications for Hydrogen Storage. Inorg. Chem. 2008, 47, 8583-8585.

(18) Staubitz, A.; Sloan, M. E.; Robertson, A. P. M.; Friedrich, A.; Schneider, S.; Gates, P. J.; Schmedt auf der Günne, J.; Manners, I. Catalytic Dehydrocoupling/Dehydrogenation of N-MethylamineBorane and Ammonia-Borane: Synthesis and Characterization of 
High Molecular Weight Polyaminoboranes. J. Am. Chem. Soc. 2010, 132, 13332-13345.

(19) Staubitz, A.; Presa Soto, A.; Manners, I. Iridium-Catalyzed Dehydrocoupling of Primary Amine-Borane Adducts: A Route to High Molecular Weight Polyaminoboranes, Boron-Nitrogen Analogues of Polyolefins. Angew. Chem., Int. Ed. 2008, 47, 6212-6215.

(20) Stubbs, N. E.; Jurca, T.; Leitao, E. M.; Woodall, C. H.; Manners, I. Polyaminoborane Main Chain Scission Using NHeterocyclic Carbenes; Formation of Donor-Stabilised Monomeric Aminoboranes. Chem. Commun. 2013, 49, 9098-9100.

(21) Han, D.; Anke, F.; Trose, M.; Beweries, T. Recent Advances in Transition Metal Catalysed Dehydropolymerisation of Amine Boranes and Phosphine Boranes. Coord. Chem. Rev. 2019, 380, 260-286.

(22) Johnson, H. C.; Hooper, T. N.; Weller, A. S. The Catalytic Dehydrocoupling of Amine-Boranes and Phosphine-Boranes. Top. Organomet. Chem. 2015, 49, 153.

(23) Rossin, A.; Peruzzini, M. Ammonia-Borane and AmineBorane Dehydrogenation Mediated by Complex Metal Hydrides. Chem. Rev. 2016, 116, 8848-8872.

(24) Resendiz-Lara, D. A.; Stubbs, N. E.; Arz, M. I.; Pridmore, N. E.; Sparkes, H. A.; Manners, I. Boron-Nitrogen Main Chain Analogues of Polystyrene: Poly(B-Aryl)Aminoboranes Via Catalytic Dehydrocoupling. Chem. Commun. 2017, 53, 11701-11704.

(25) Resendiz-Lara, D. A.; Whittell, G. R.; Leitao, E. M.; Manners, I. Catalytic Synthesis, Characterization, and Properties of Polyaminoborane Homopolymers and Random Copolymers. Macromolecules 2019, 52, 7052-7064.

(26) Knitsch, R.; Han, D.; Anke, F.; Ibing, L.; Jiao, H.; Hansen, M. R.; Beweries, T. Fe(II) Hydride Complexes for the Homogeneous Dehydrocoupling of Hydrazine Borane: Catalytic Mechanism Via DFT Calculations and Detailed Spectroscopic Characterization. Organometallics 2019, 38, 2714-2723.

(27) Anke, F.; Boye, S.; Spannenberg, A.; Lederer, A.; Heller, D.; Beweries, T. Dehydropolymerisation of Methylamine Borane and an N-Substituted Primary Amine Borane Using a PNP Fe Catalyst. Chem. - Eur. J. 2020, 26, 7889-7899.

(28) Jurca, T.; Dellermann, T.; Stubbs, N. E.; Resendiz-Lara, D. A.; Whittell, G. R.; Manners, I. Step-Growth Titanium-Catalysed Dehydropolymerisation of Amine-Boranes. Chem. Sci. 2018, 9, $3360-3366$.

(29) Colebatch, A. L.; Hawkey-Gilder, B. W.; Whittell, G. R.; Oldroyd, N. L.; Manners, I.; Weller, A. S. A General, RhodiumCatalyzed, Synthesis of Deuterated Boranes and N-Methyl Polyaminoboranes. Chem. - Eur. J. 2018, 24, 5450-5455.

(30) Devillard, M.; De Albuquerque Pinheiro, C. A.; Caytan, E.; Roiland, C.; Dinoi, C.; Del Rosal, I.; Alcaraz, G. Uncatalyzed Formation of Polyaminoboranes from Diisopropylaminoborane and Primary Amines: A Kinetically Controlled Polymerization Reaction. Adv. Synth. Catal. 2021, 363, 2417-2426.

(31) De Albuquerque Pinheiro, C. A.; Roiland, C.; Jehan, P.; Alcaraz, G. Solventless and Metal-Free Synthesis of High-MolecularMass Polyaminoboranes from Diisopropylaminoborane and Primary Amines. Angew. Chem., Int. Ed. 2018, 57, 1519-1522.

(32) Metters, O. J.; Chapman, A. M.; Robertson, A. P. M.; Woodall, C. H.; Gates, P. J.; Wass, D. F.; Manners, I. Generation of Aminoborane Monomers RR' $=\mathrm{BH}_{2}$ from Amine-Boronium Cations [RR'NH- $\left.\mathrm{BH}_{2} \mathrm{~L}\right]^{+}$: Metal Catalyst-Free Formation of Polyaminoboranes at Ambient Temperature. Chem. Commun. 2014, 50, 12146-12149.

(33) Trose, M.; Reiß, M.; Reiß, F.; Anke, F.; Spannenberg, A.; Boye, S.; Lederer, A.; Arndt, P.; Beweries, T. Dehydropolymerisation of Methylamine Borane Using a Dinuclear 1,3-Allenediyl Bridged Zirconocene Complex. Dalton Trans. 2018, 47, 12858-12862.

(34) Todisco, S.; Luconi, L.; Giambastiani, G.; Rossin, A.; Peruzzini, M.; Golub, I. E.; Filippov, O. A.; Belkova, N. V.; Shubina, E. S. Ammonia Borane Dehydrogenation Catalyzed by $\left(\kappa^{4}-\mathrm{EP}_{3}\right) \mathrm{Co}(\mathrm{H})$ $\left[\mathrm{EP}_{3}=\mathrm{E}\left(\mathrm{CH}_{2} \mathrm{CH}_{2} \mathrm{PPh}_{2}\right)_{3} ; \mathrm{E}=\mathrm{N}, \mathrm{P}\right]$ and $\mathrm{H}_{2}$ Evolution from Their Interaction with $\mathrm{NH}$ Acids. Inorg. Chem. 2017, 56, 4296-4307.
(35) Hasche, P.; Haak, J.; Anke, F.; Kubis, C.; Baumann, W.; Drexler, H.-J.; Jiao, H.; Beweries, T. Dehydropolymerisation of Methylamine Borane Using Highly Active Rhodium(III) Bis(Thiophosphinite) Pincer Complexes: Catalytic and Mechanistic Insights. Catal. Sci. Technol. 2021, 11, 3514-3526.

(36) Baker, R. T.; Gordon, J. C.; Hamilton, C. W.; Henson, N. J.; Lin, P.-H.; Maguire, S.; Murugesu, M.; Scott, B. L.; Smythe, N. C. Iron Complex-Catalyzed Ammonia-Borane Dehydrogenation. A Potential Route toward B-N-Containing Polymer Motifs Using Earth-Abundant Metal Catalysts. J. Am. Chem. Soc. 2012, 134, 55985609.

(37) LaPierre, E. A.; Patrick, B. O.; Manners, I. Trivalent Titanocene Alkyls and Hydrides as Well-Defined, Highly Active, and Broad Scope Precatalysts for Dehydropolymerization of Amine-Boranes. J. Am. Chem. Soc. 2019, 141, 20009-20015.

(38) Anke, F.; Han, D.; Klahn, M.; Spannenberg, A.; Beweries, T. Formation of High-Molecular Weight Polyaminoborane by $\mathrm{Fe}$ Hydride Catalysed Dehydrocoupling of Methylamine Borane. Dalton Trans. 2017, 46, 6843-6847.

(39) Glüer, A.; Förster, M.; Celinski, V. R.; Schmedt auf der Günne, J.; Holthausen, M. C.; Schneider, S. Highly Active Iron Catalyst for Ammonia Borane Dehydrocoupling at Room Temperature. ACS Catal. 2015, 5, 7214-7217.

(40) Marziale, A. N.; Friedrich, A.; Klopsch, I.; Drees, M.; Celinski, V. R.; Schmedt auf der Günne, J.; Schneider, S. The Mechanism of Borane-Amine Dehydrocoupling with Bifunctional Ruthenium Catalysts. J. Am. Chem. Soc. 2013, 135, 13342-13355.

(41) Boyd, T. M.; Andrea, K. A.; Baston, K.; Johnson, A.; Ryan, D. E.; Weller, A. S. A Simple Cobalt-Based Catalyst System for the Controlled Dehydropolymerisation of $\mathrm{H}_{3} \mathrm{~B} \cdot \mathrm{NMeH}_{2}$ on the GramScale. Chem. Commun. 2020, 56, 482-485.

(42) Dallanegra, R.; Robertson, A. P. M.; Chaplin, A. B.; Manners, I.; Weller, A. S. Tuning the $\left[\mathrm{L}_{2} \mathrm{Rh} \cdots \mathrm{H}_{3} \mathrm{~B} \cdot \mathrm{NR}_{3}\right]^{+}$Interaction Using Phosphine Bite Angle. Demonstration by the Catalytic Formation of Polyaminoboranes. Chem. Commun. 2011, 47, 3763-3765.

(43) Adams, G. M.; Ryan, D. E.; Beattie, N. A.; McKay, A. I.; LloydJones, G. C.; Weller, A. S. Dehydropolymerization of $\mathrm{H}_{3} \mathrm{~B} \cdot \mathrm{NMeH}_{2}$ Using a $[\mathrm{Rh}(\mathrm{DPEphos})]^{+}$Catalyst: The Promoting Effect of $\mathrm{NMeH}_{2}$. ACS Catal. 2019, 9, 3657-3666.

(44) Ryan, D. E.; Andrea, K. A.; Race, J. J.; Boyd, T. M.; LloydJones, G. C.; Weller, A. S. Amine-Borane Dehydropolymerization Using Rh-Based Precatalysts: Resting State, Chain Control, and Efficient Polymer Synthesis. ACS Catal. 2020, 10, 7443-7448.

(45) Johnson, H. C.; Leitao, E. M.; Whittell, G. R.; Manners, I.; Lloyd-Jones, G. C.; Weller, A. S. Mechanistic Studies of the Dehydrocoupling and Dehydropolymerization of Amine-Boranes Using a $[\mathrm{Rh} \text { (Xantphos) }]^{+}$Catalyst. J. Am. Chem. Soc. 2014, 136, 9078-9093.

(46) Adams, G. M.; Colebatch, A. L.; Skornia, J. T.; McKay, A. I.; Johnson, H. C.; Lloyd-Jones, G. C.; Macgregor, S. A.; Beattie, N. A.; Weller, A. S. Dehydropolymerization of $\mathrm{H}_{3} \mathrm{~B} \cdot \mathrm{NMeH}_{2}$ to Form Polyaminoboranes Using [Rh(Xantphos-Alkyl)] Catalysts. J. Am. Chem. Soc. 2018, 140, 1481-1495.

(47) Bhunya, S.; Malakar, T.; Paul, A. Unfolding the Crucial Role of a Nucleophile in Ziegler-Natta Type Ir Catalyzed Polyaminoborane Formation. Chem. Commun. 2014, 50, 5919-5922.

(48) Peterson, G. I.; Choi, T.-L. Cascade Polymerizations: Recent Developments in the Formation of Polymer Repeat Units by Cascade Reactions. Chem. Sci. 2020, 11, 4843-4854.

(49) Pons, V.; Baker, R. T.; Szymczak, N. K.; Heldebrant, D. J.; Linehan, J. C.; Matus, M. H.; Grant, D. J.; Dixon, D. A. Coordination of Aminoborane, $\mathrm{NH}_{2} \mathrm{BH}_{2}$, Dictates Selectivity and Extent of $\mathrm{H}_{2}$ Release in Metal-Catalysed Ammonia Borane Dehydrogenation. Chem. Commun. 2008, 44, 6597-6599.

(50) Head-to-tail chain propagation has been shown to operate in closely related phosphido-borane polymerization: Marquardt, C.; Jurca, T.; Schwan, K.-C.; Stauber, A.; Virovets, A. V.; Whittell, G. R.; Manners, I.; Scheer, M. Metal-Free Addition/Head to Tail Polymerization of Transient Phosphinoboranes, $\mathrm{RPH}-\mathrm{BH}_{2}$ : A Route to 
Poly(Alkylphosphinoboranes). Angew. Chem., Int. Ed. 2015, 54, 13782-13786.

(51) Jenkins, A. D.; Jones, R. G.; Moad, G. Terminology for Reversible-Deactivation Radical Polymerization Previously Called "Controlled" Radical or "Living" Radical Polymerization (IUPAC Recommendations 2010). Pure Appl. Chem. 2009, 82, 483-491.

(52) Roselló-Merino, M.; López-Serrano, J.; Conejero, S. Dehydrocoupling Reactions of Dimethylamine-Borane by $\mathrm{Pt}(\mathrm{II}) \mathrm{Com}-$ plexes: A New Mechanism Involving Deprotonation of Boronium Cations. J. Am. Chem. Soc. 2013, 135, 10910-10913.

(53) Spearing-Ewyn, E. A. K.; Beattie, N. A.; Colebatch, A. L.; Martinez-Martinez, A. J.; Docker, A.; Boyd, T. M.; Baillie, G.; Reed, R.; Macgregor, S. A.; Weller, A. S. The Role of Neutral Rh(PONOP)$\mathrm{H}$, Free $\mathrm{NMe}_{2} \mathrm{H}$, Boronium and Ammonium Salts in the Dehydrocoupling of Dimethylamine-Borane Using the Cationic Pincer $\left[\mathrm{Rh}(\mathrm{PONOP})\left(\eta^{2}-\mathrm{H}_{2}\right)\right]^{+}$Catalyst. Dalton Trans. 2019, 48, 14724-14736.

(54) Alig, L.; Fritz, M.; Schneider, S. First-Row Transition Metal (De)Hydrogenation Catalysis Based on Functional Pincer Ligands. Chem. Rev. 2019, 119, 2681-2751.

(55) For facially coordinated ${ }^{i} \operatorname{Pr}(\mathrm{PNP})$ ligands that also display $\mathrm{N}-$ $\mathrm{H} \cdots \mathrm{Cl}$ hydrogen bonding, see: Friedrich, A.; Drees, M.; Käss, M.; Herdtweck, E.; Schneider, S. Ruthenium Complexes with Cooperative Pnp-Pincer Amine, Amido, Imine, and Enamido Ligands: Facile Ligand Backbone Functionalization Processes. Inorg. Chem. 2010, 49, 5482-5494 and references therein.

(56) Alvarez, S. A Cartography of the Van Der Waals Territories. Dalton Trans. 2013, 42, 8617-8636.

(57) (a) Burk, M. J.; Feaster, J. E.; Harlow, R. L. New Chiral Phospholanes; Synthesis, Characterization, and Use in Asymmetric Hydrogenation Reactions. Tetrahedron: Asymmetry 1991, 2, 569-592. (b) Rozenel, S. S.; Padilla, R.; Camp, C.; Arnold, J. Unusual Activation of $\mathrm{H}_{2}$ by Reduced Cobalt Complexes Supported by a PNP Pincer Ligand. Chem. Commun. 2014, 50, 2612-2614. (c) Clarke, Z. E.; Maragh, P. T.; Dasgupta, T. P.; Gusev, D. G.; Lough, A. J.; AbdurRashid, K. A Family of Active Iridium Catalysts for Transfer Hydrogenation of Ketones. Organometallics 2006, 25, 4113-4117.

(58) Moxham, G. L.; Randell-Sly, H.; Brayshaw, S. K.; Weller, A. S.; Willis, M. C. Intermolecular Alkene and Alkyne Hydroacylation with B-S-Substituted Aldehydes: Mechanistic Insight into the Role of a Hemilabile P-O-P Ligand. Chem. - Eur. J. 2008, 14, 8383-8397.

(59) Confer, M. P.; DeSimone, A.; Burnham, H.; McLeod, W.; Klein, T. M.; Street, S. C.; Dixon, D. A. Solubility Thermodynamics of Amine Boranes in Polar Solvents. Int. J. Hydrogen Energy 2021, 46, 10801-10808.

(60) There is no evidence for the formation of poly(THF) from the ${ }^{1} \mathrm{H}$ NMR spectrum, see: Tezuka, Y.; Tsuchitani, A.; Oike, H. Synthesis of Polymeric Topological Isomers through Electrostatic Self-Assembly and Covalent Fixation with Star Telechelic Precursors. Macromol. Rapid Commun. 2004, 25, 1531-1535. Isolated polymer showed trace entrained THF ( $\delta 1.82$ and 3.72).

(61) Widegren, J. A.; Finke, R. G. A Review of the Problem of Distinguishing True Homogeneous Catalysis from Soluble or Other Metal-Particle Heterogeneous Catalysis under Reducing Conditions. J. Mol. Catal. A: Chem. 2003, 198, 317-341.

(62) While $[1] \mathrm{Cl}$ is sparingly soluble in THF- $d_{8}$, at the low catalyst loading used $(\sim 2-3 \mathrm{mg} / \mathrm{mL})$ clear, homogeneous solutions are formed, and induction periods get longer with lower catalyst loadings and are affected by amine-borane isotopologue-all indicating that limiting solubility is not the cause of the observed induction phases. (63) Sewell, L. J.; Huertos, M. A.; Dickinson, M. E.; Weller, A. S.; Lloyd-Jones, G. C. Dehydrocoupling of Dimethylamine Borane Catalyzed by $\mathrm{Rh}\left(\mathrm{PCy}_{3}\right)_{2} \mathrm{H}_{2} \mathrm{Cl}$. Inorg. Chem. 2013, 52, 4509-4516.

(64) Strong correlations are observed between $\delta-8.53\left(\mathrm{H}_{\mathrm{A}}\right)$ and $\delta$ $3.86(\mathrm{NH})$ in a NOESY spectrum, as well as between $\delta-18.24\left(\mathrm{H}_{\mathrm{B}}\right)$ in the other two hydrides. Trans-orientated $\mathrm{H}_{\mathrm{A}}$ and $\mathrm{H}_{\mathrm{C}}(\delta-8.83)$ are also assigned by their distinctive chemical shifts that are generally observed between $\sim \delta-6$ and -10 . For examples of trans-dihydrides, see: (a) Grellier, M.; Vendier, L.; Sabo-Etienne, S. Ruthenium
Complexes Carrying Hydride, Dihydrogen, and Phosphine Ligands: Reversible Hydrogen Release. Angew. Chem., Int. Ed. 2007, 46, 26132615. (b) Bertoli, M.; Choualeb, A.; Gusev, D. G.; Lough, A. J.; Major, Q.; Moore, B. PNP Pincer Osmium Polyhydrides for Catalytic Dehydrogenation of Primary Alcohols. Dalton Trans. 2011, 40, 89418949.

(65) Chen, X.; Zhao, J.-C.; Shore, S. G. The Roles of Dihydrogen Bonds in Amine Borane Chemistry. Acc. Chem. Res. 2013, 46, 26662675.

(66) Other binding motifs were explored. We cannot discount additional outersphere interactions from other amine boranes that contribute disproportionately to the chemical shift change in $\mathrm{H}_{B}$, which is not captured in these calculations.

(67) Bhunya, S.; Malakar, T.; Ganguly, G.; Paul, A. Combining Protons and Hydrides by Homogeneous Catalysis for Controlling the Release of Hydrogen from Ammonia-Borane: Present Status and Challenges. ACS Catal. 2016, 6, 7907-7934.

(68) Titova, E. M.; Osipova, E. S.; Pavlov, A. A.; Filippov, O. A.; Safronov, S. V.; Shubina, E. S.; Belkova, N. V. Mechanism of Dimethylamine-Borane Dehydrogenation Catalyzed by an Iridium(III) PCP-Pincer Complex. ACS Catal. 2017, 7, 2325-2333.

(69) Luconi, L.; Osipova, E. S.; Giambastiani, G.; Peruzzini, M.; Rossin, A.; Belkova, N. V.; Filippov, O. A.; Titova, E. M.; Pavlov, A. A.; Shubina, E. S. Amine Boranes Dehydrogenation Mediated by an Unsymmetrical Iridium Pincer Hydride: (PCN) vs (PCP) Improved Catalytic Performance. Organometallics 2018, 37, 3142-3153.

(70) Garralda, M. A.; Mendicute-Fierro, C.; Rodríguez-Diéguez, A.; Seco, J. M.; Ubide, C.; Zumeta, I. Efficient Hydridoirida- $\beta$-DiketoneCatalyzed Hydrolysis of Ammonia- or Amine-Boranes for Hydrogen Generation in Air. Dalton Trans. 2013, 42, 11652-11660.

(71) The processes that brings $[\mathbf{1}] \mathbf{C l}$ online will be the topic of a future contribution.

(72) Kaminsky, W. Discovery of Methylaluminoxane as Cocatalyst for Olefin Polymerization. Macromolecules 2012, 45, 3289-3297.

(73) Bray, J. T. W.; Ford, M. J.; Karadakov, P. B.; Whitwood, A. C.; Fairlamb, I. J. S. The Critical Role Played by Water in Controlling Pd Catalyst Speciation in Arylcyanation Reactions. React. Chem. Eng. 2019, 4, 122-130.

(74) Patmore, N. J.; Hague, C.; Cotgreave, J. H.; Mahon, M. F.; Frost, C. G.; Weller, A. S. Silver Phosphanes Partnered with Carborane Monoanions: Synthesis, Structures and Use as Highly Active Lewis Acid Catalysts in a Hetero-Diels-Alder Reaction. Chem. - Eur. J. 2002, 8, 2088-2098.

(75) Bray, K. L.; Charmant, J. P. H.; Fairlamb, I. J. S.; Lloyd-Jones, G. C. Structural and Mechanistic Studies on the Activation and Propagation of a Cationic Allylpalladium Procatalyst in 1,6-Diene Cycloisomerization. Chem. - Eur. J. 2001, 7, 4205-4215.

(76) Using [1] Cl and 2 both produces a D-labeled polymer that has a smaller $M_{\mathrm{n}}\left(\sim 60000 \mathrm{~g} \mathrm{~mol}^{-1}\right)$ and N-labeled longer $M_{\mathrm{n}}(73000-$ $94000 \mathrm{~g} \mathrm{~mol}^{-1}$ ). We are reluctant to interpret this in terms of possible chain transfer mechanisms, as the magnitude of noncovalent interactions $(\mathrm{N}-\mathrm{H} \cdots \mathrm{H}-\mathrm{B})$, and thus the conformation of the polymer in solution, will likely be affected by isotopic substitution. A similar trend has been noted previously, see ref 29.

(77) Addition of acids, $\mathrm{HX}$, to amino-boranes $\mathrm{H}_{2} \mathrm{~B}=\mathrm{NR}_{2}$ results in products such as $\mathrm{H}_{2} \mathrm{XB}-\mathrm{NR}_{2} \mathrm{H}$, in the case here $\mathrm{HX}=\left[\mathrm{NMeH}_{3}\right] \mathrm{Cl}$. For example, see: Leitao, E. M.; Manners, I. Rehydrogenation of Aminoboranes to Amine-Boranes Using $\mathrm{H}_{2} \mathrm{O}$ : Reaction Scope and Mechanism. Eur. J. Inorg. Chem. 2015, 2015, 2199-2205.

(78) See the Supporting Information.

(79) Inoue, M.; Kodama, G. Preparation and Some Properties of Dihydridobis (Monomethylamine)- and Dihydridobis(Dimethylamine)Boron(III) Tetrahydridoborate(III). Inorg. Chem. 1968, 7, 430-433.

(80) Bellham, P.; Hill, M. S.; Kociok-Köhn, G.; Liptrot, D. J. Bespoke Synthesis of Unsymmetrical Diaminoboranes by Alkaline Earth Catalysis. Chem. Commun. 2013, 49, 1960-1962. 
(81) Stephens, F. H.; Baker, R. T.; Matus, M. H.; Grant, D. J.; Dixon, D. A. Acid Initiation of Ammonia-Borane Dehydrogenation for Hydrogen Storage. Angew. Chem., Int. Ed. 2007, 46, 746-749.

(82) A future contribution will report the synthesis of $[\mathbf{1}]\left[\mathbf{B A r}^{\mathrm{F}}{ }_{4}\right]$ and its use as a poor dehydropolymerization catalyst.

(83) Gunanathan, C.; Milstein, D. Bond Activation and Catalysis by Ruthenium Pincer Complexes. Chem. Rev. 2014, 114, 12024-12087.

(84) Riehl, J. F.; Jean, Y.; Eisenstein, O.; Pelissier, M. Theoretical Study of the Structures of Electron-Deficient $\mathrm{d}^{6} \mathrm{ML}_{5}$ Complexes. Importance of a $\pi$-Donating Ligand. Organometallics 1992, 11, 729737.

(85) Macgregor, S. A.; MacQueen, D. Theoretical Study of the Electronic Structure of Group $6\left[\mathrm{M}(\mathrm{CO})_{5} \mathrm{X}\right]^{-}$Species $\left(\mathrm{X}=\mathrm{NH}_{2}\right.$, $\mathrm{OH}$, Halide, $\mathrm{H}, \mathrm{CH}_{3}$ ) and a Reinvestigation of the Role of $\pi$-Donation in CO Lability. Inorg. Chem. 1999, 38, 4868-4876.

(86) Although similar to the mechanisms proposed by Beweries (ref 38 ) and Schneider (refs 39, 40), the extent of $\pi$-stabilization in those systems is more limited as they do not form a dihydride intermediate such as $\operatorname{Int}(\mathbf{C}-\mathbf{D})$.

(87) An alternative pathway in which $\mathrm{H}_{2}$ loss occurred directly from Int $(3 \cdot \mathrm{AB}-\mathrm{C})$ to form $\mathrm{D}$ involved a transition state at $+23.1 \mathrm{kcal}$ $\mathrm{mol}^{-1}$. This implies $\pi$-donation from the amide ligand is worth approximately $3.5 \mathrm{kcal} \mathrm{mol}^{-1}$.

(88) The direct formation of $\mathbf{C}$ from $3-\mathbf{A B}$ was also defined, but involved a higher-lying transition state at $26.7 \mathrm{kcal} / \mathrm{mol}$. In contrast, the-reversible-reductive elimination of $\mathrm{H}_{2}$ from $3-\mathbf{A B}$ has an overall barrier of only $17.0 \mathrm{kcal} \mathrm{mol}{ }^{-1}$ to form monohydride $\mathrm{Rh}(\mathrm{PNPH}) \mathrm{H}$. As the formation of $\operatorname{Int}(\mathrm{C}-\mathrm{D})$ from this species entails a high energy transition state $\left[32.1 \mathrm{kcal} \mathrm{mol}^{-1}\right]$, this suggests that while $\mathrm{Rh}(\mathrm{PNPH}) \mathrm{H}$ could be catalytically competent; this will only happen in the presence of $\mathrm{H}_{2}$ to reform 3-AB. See the Supporting Information for supporting experimental data.

(89) Kumar, A.; Johnson, H. C.; Hooper, T. N.; Weller, A. S.; Algarra, A. G.; Macgregor, S. A. Multiple Metal-Bound Oligomers from Ir-Catalysed Dehydropolymerisation of $\mathrm{H}_{3} \mathrm{~B} \cdot \mathrm{NH}_{3}$ as Probed by Experiment and Computation. Chem. Sci. 2014, 5, 2546-2553.

(90) Xu, P.; Xu, X. Dehydrogenation of (Di)Amine-Boranes by Highly Active Scandocene Alkyl Catalysts. Organometallics 2019, 38, 3212-3217.

(91) Lennox, A. J. J.; Lloyd-Jones, G. C. Organotrifluoroborate Hydrolysis: Boronic Acid Release Mechanism and an Acid-Base Paradox in Cross-Coupling. J. Am. Chem. Soc. 2012, 134, 7431-7441.

(92) Luo, J.; Wu, Y.; Zijlstra, H. S.; Harrington, D. A.; McIndoe, J. S. Mass Transfer and Convection Effects in Small-Scale Catalytic Hydrogenation. Catal. Sci. Technol. 2017, 7, 2609-2615.

(93) Johnson, H. C.; Robertson, A. P. M.; Chaplin, A. B.; Sewell, L. J.; Thompson, A. L.; Haddow, M. F.; Manners, I.; Weller, A. S. Catching the First Oligomerization Event in the Catalytic Formation of Polyaminoboranes: $\mathrm{H}_{3} \mathrm{~B} \cdot \mathrm{NMeHBH}_{2} \cdot \mathrm{NMeH}_{2}$ Bound to Iridium. J. Am. Chem. Soc. 2011, 133, 11076-11079.

(94) Other shape models could have been used in this analysis.

(95) The phenomenon of solvent induced crazing has been well studied. See, for example: Volynskii, L.; Bakeev, N. F. Studies in Polymer Science 13: Solvent Crazing of Polymers; Elsevier: Amsterdam, 1995.

(96) Karunakaran, M.; Nunes, S. P.; Qiu, X.; Yu, H.; Peinemann, K.V. Isoporous PS-b-PEO Ultrafiltration Membranes Via Self-Assembly and Water-Induced Phase Separation. J. Membr. Sci. 2014, 453, 471477. 